\title{
EL DERECHO EN LA CRISIS ALIMENTARIA DE LA EPIDEMIA DE SOBREPESO Y OBESIDAD
}

\author{
THE RIGHT IN THE FOOD CRISIS OF THE EPIDEMIC OF OVERWEIGHT AND \\ OBESITY
}

\author{
Pablo Miró Colmenarez \\ Doctor por la Universidad Católica San Antonio de Murcia. Máster en estudios sobre la \\ Unión Europea. Licenciado en Derecho. E-mail: pjmiro@ucam.edu
}

Convidado

Doi: $10.5585 / \mathrm{rdb} . v 18 \mathrm{i} 7.801$

\begin{abstract}
RESUMEN: Las soluciones al problema de sobrepeso y obesidad como fenómeno epidemiológico ha estado ausente de enfoques jurídicos. En este sentido este trabajo pretende aproximarse al estudio del rol del Derecho ante el problema de la epidemia de sobrepeso y obesidad. Para ello se examina el concepto de alimento con el objeto de determinar la naturaleza de los productos ultraprocesados y sus implicaciones jurídicas, y se analiza el pael de la industria y su influencia en el diseño de las políticas públicas. Asimismo se propone el concepto de salud alimentaria como objeto de un incipiente Derecho alimentario aún por cristalizar, pero que cuyos principios están llamado a regular las complejas relaciones sociales que se derivan del hecho alimentario.
\end{abstract}

Palabras Clave: Alimento, salud alimentaria, derecho alimentario, sustancias sintéticas

\begin{abstract}
The problem of overweight and obesity as an epidemiological phenomenon have been absent from legal approaches. This paper studies the role of the Law in the face of this epidemic. In this sense, the concept of food is examined in order to determine the nature of ultraprocessed products and their legal implications. Likewise, the role of the industry and its influence on the design of public policies are analyzed. Finally it propouses the concept of "Food Health" as the principal subject of an incipient Food Law yet to crystallize, whose principles are called to regulate the complex social relationships that derive from the food facts.
\end{abstract}

Key Words: Food, health food, food law, consumable synthetic substances, ESO.

SUMARIO: I. Enfoques de intervención pública en las que se basan las estrategias contra la epidemia de sobrepeso y obesidad. 1.1 La naturaleza de la Epidemia de Sobrepeso y Obesidad desde una perspectiva jurídica.1.2 El concepto jurídico de alimento.1.3. El concepto de salud alimentaria. 1.3.1. La seguridad alimentaria .1.3.2. La inocuidad de los alimentos. 1.3.3. La seguridad nutricional. 1.3.4 Evolución de las normas de la salud alimentaria. 2. La industria alimentaria y el diseño de las políticas públicas.2.1 Los sistemas de regulación voluntaria. 2.2 El Derecho de la alimentación. 3. Los productos ultra procesados, la eso y el derecho. 3.1. Criterios para la clasificación de los alimentos. 3.2. Características problemáticas de los productos ultra procesados. 3.3 Naturaleza de los Productos ultra procesados como producto alimentario y consideraciones jurídicas. 4. Bibliografia. 


\section{ENFOQUES DE INTERVENCIÓN PÚBLICA EN LAS QUE SE BASAN LAS ESTRATEGIAS CONTRA LA EPIDEMIA DE SOBREPESO Y OBESIDAD}

En la literatura científica se encuentran en general dos enfoques a la hora de abordar los problemas de salud pública, y más en concreto los que tienen que ver con la Epidemia de Sobrepeso y Obesidad (ESO). ${ }^{1}{ }^{2}$ Por un lado se encuentra el enfoque de la responsabilidad individual; y por otro, el enfoque que considera la existencia de un marco sistémico que atribuye la responsabilidad al entorno, por lo que el Estado está en la obligación de intervenir para proteger la salud pública. ${ }^{3}$

La responsabilidad individual es una ideología que sugiere que el sobrepeso y obesidad de las personas, es causa de su propio comportamiento irresponsable al elegir productos alimentarios no saludables y llevar un estilo de vida sedentario. Centra la cuestión en la conducta de las personas. Este planteamiento, excluye cualquier otro factor involucrado en el aumento de la prevalencia de la epidemia, como factores ambientales, el papel de la industria alimentaria, y las propias políticas públicas. ${ }^{4}$ La idea de que la causa del problema de la ESO se localiza en las personas, implica que todas las acciones y medidas que se tomen para luchar contra la epidemia, ya sean de naturaleza jurídica como si no, se centren en el individuo, y se ignore el resto de factores. Desde una perspectiva epidemiológica, sería como intentar luchar contra una epidemia, tratando al huésped, pero ignorando al agente patógeno y al vector. Por otro lado, la responsabilidad individual, defiende la flexibilización de las normas jurídicas que regulan a la industria alimentaria en materias como la composición nutricional de los productos ultra procesados, el marketing, el etiquetado alimentario, la relación de la industria con el sector público, entre otros. Los intentos por regular estas materias a través de instrumentos jurídicos coercitivos, que vayan más allá de los sistemas regulación voluntaria, son acusados de atentar contra la libertad de las personas, invadir aspectos de su vida privada, y su derecho a elegir qué, cuánto, dónde y cómo comer. Asimismo, cualquier iniciativa por regular estas materias es visto por los defensores de las ideologías de la responsabilidad individual, como una intervención excesiva del Estado que demoniza a la industria alimentaria y promueve el Nanny State. ${ }^{5}$

Los trabajos más recientes en el ámbito de la ESO, convienen en señalar que las estrategias para abordar eficazmente el problema de salud pública que supone la epidemia de sobre peso y obesidad, se sitúa dentro del segundo enfoque; el que defiende que el Estado debe intervenir para proteger la salud pública. Efectivamente se observa que los entornos alimentarios actuales no son propicios para que las personas puedan hacer elecciones alimentarias libres y bien informadas. De hecho, "la investigación sobre los factores que determinan conductas como fumar, hacer ejercicio o la alimentación, revelan que estos factores no dependen simplemente de decisiones libres e independientes, sino que se ven influidas por factores del entorno de gran alcance". ${ }^{6}$ La concurrencia de ciertos factores como el marketing agresivo, la manipulación de

\footnotetext{
1 Vid. ROBERTO, Christina A. et al.: "Patchy progress on obesity prevention: emerging examples, entrenched barriers, and new thinkin"g. The Lancet, 2015, vol. 385, no 9985, pág. 2400-2409. (1)

2 Vid. POMERANZ, Jennifer L.; ROBERTO, Christina A.: “The Impact of 'Food Addiction'on Food Policy". Current Addiction Reports, 2014, vol. 1, no 2, pág. 103

${ }^{3}$ Vid. POMERANZ, Jennifer L.; ROBERTO, Christina A. Op. Cit, pág. 103.

${ }^{4}$ Vid. BROWNELL, Kelly D. et al.: "Personal responsibility and obesity: a constructive approach to a controversial issue". Health Affairs, 2010, vol. 29, no 3, pág. 379.

${ }^{5}$ Vid. BROWNELL, Kelly D. et al.: "Personal responsibility and obesity: a constructive approach to a controversial issue". Health Affairs, 2010, vol. 29, no 3, pág. 379.

${ }^{6}$ Traducción propia: "Research on the determinants of smoking, exercising, and eating behavior reveals that these are not simply free and independent choices by individuals, but rather are influenced by powerful environmental factors." Véase BROWNELL, Kelly D. et al.: "Personal responsibility and obesity: a constructive approach to a controversial issue". Health Affairs, 2010, vol. 29, no 3, pág. 382.
}

Revista de Direito Brasileira | São Paulo, SP | v. 18 | n. 7 | p. 463 - 503 | Set./Dez. 2017 
las preferencias alimentarias, la utilización de sustancias adictivas en los productos ultra procesados, y la interferencia por parte de la industria en el diseño de las políticas públicas, entre otros; señalan la existencia de entornos alimentarios tóxicos, en los que se observa una explotación de vulnerabilidades psicológicas, biológicas y socioeconómicas de las personas, ${ }^{7}$ que por lo tanto compromete seriamente los argumentos de los defensores de la responsabilidad individual.

Por otro lado, se observa que las teorías de responsabilidad individual resultan altamente ineficientes. Las políticas diseñadas para hacer intervenciones estructurales, tienen un impacto positivo y más eficiente en el entorno, que si se estas políticas se conciben para que sean aplicadas a los individuos y por los individuos, tomando en cuenta que en las intervenciones estructurales, los individuos no ejecutan ningún precepto o no son conscientes de ello. ${ }^{8}$ Por ejemplo, es mucho más eficiente y eficaz poner en marcha un sistema de tratamiento de aguas para impedir enfermedades como el cólera, que pedirle a cada persona que se encargue de purificar su agua. $^{9}$

En lo que concierne a la ESO, los argumentos de la teoría de la responsabilidad personal no se sostienen, porque la existencia de entornos alimentarios tóxicos, afectados por una serie de factores problemáticos que limitan la capacidad de las personas de hacer elecciones alimentarias saludables. En ese sentido, existe consenso en la literatura científica en recomendar una intervención estatal más fuerte, a través de herramientas jurídicas más eficaces como la ley, en lugar de los sistemas de regulación voluntaria.

Asimismo, se observa que "los factores de los entornos tóxicos explotan las vulnerabilidades biológicas, psicológicas y socioeconómicas de las personas, con el fin de promover el consumo de productos ultra procesados." ${ }^{10}$ En definitiva, las políticas públicas anti obesidad basadas en la responsabilidad personal de los consumidores no sólo no han servido para frenar la epidemia de sobrepeso y obesidad, sino que más bien han contribuido a que se perpetúen las condiciones que favorecen el aumento de la prevalencia de la epidemia; ${ }^{11}$ aunque por otro lado, sí ha beneficiado los intereses económicos de la industria alimentaria. ${ }^{12}$ De la opción por una u otra alternativa depende la aceptación de un determinado concepto de alimento.

\subsection{La naturaleza de la Epidemia de Sobrepeso y Obesidad desde una perspectiva jurídica}

Hoy podemos hablar de de sobrepeso y obesidad de alcance epidémico con independencia de las causas derivadas de desórdenes genéticos, endocrinos o de otra naturaleza. La la bibliografía científica conecta directamente ésta con el aumento de la oferta de determinados productos alimentarios, que presentan ciertas características negativas tales como alta densidad energética y su escaso valor nutricional. ${ }^{13}$ En general se suele considerar que el

\footnotetext{
${ }^{7}$ Vid. ROBERTO, Christina A. et al.: "Patchy progress on obesity prevention: emerging examples, entrenched barriers, and new thinking". The Lancet, 2015, vol. 385, no 9985, pág. 2400-2409. (1)

${ }^{8}$ Vid. KATZ, Mitchell H.: "Structural interventions for addressing chronic health problems." JAMA, 2009, vol. 302, no 6, pág. 683.

${ }^{9}$ Vid. BROWNELL, Kelly D. et al.: "Personal responsibility and obesity: a constructive approach to a controversial issue". Health Affairs, 2010, vol. 29, no 3, pág. 382.

10 Traducción propia: ""...environmental factors exploit biological, psychological, social, and economic vulnerabilities that promote overconsumption of unhealthy foods." Véase ROBERTO, Christina A. et al. Op.Cit.Pág. 2400-2409. (2)

${ }^{11}$ Vid. SWINBURN, Boyd, et al.: "Strengthening of accountability systems to create healthy food environments and reduce global obesity". The Lancet, 2015, vol. 385, no 9986, pág. 2534-2545. (2)

${ }^{12}$ Vid. LUSTIG, Robert H.: Fat chance: beating the odds against sugar, processed food, obesity, and disease. Penguin, 2012, pág. 233

13 Vid. SWINBURN, Boyd A. et al:: "The global obesity pandemic: shaped by global drivers and local environments." The Lancet, 2011, vol. 378, no 9793, pág. 807.
} 
problema de sobrepeso y obesidad tiene una naturaleza multifactorial. ${ }^{14}{ }^{15}$ Estos múltiples factores pueden ser genéticos, hormonales, psicológicos, ambientales, económicos, alimentarios, etc. No obstante, el aumento de la prevalencia de sobrepeso y obesidad se produjo a partir de la década de los 80 , fundamentalmente debido a transiciones nutricionales, que produjeron cambios adversos en la dieta de las personas. Estos cambios consistieron en un aumento del consumo de productos alimentarios energéticamente densos y nutricionalmente pobres y una disminución en la ingesta de carbohidratos complejos, de alimentos ricos en fibra, frutas y verduras. ${ }^{16}$ Por sus causas y por sus efectos podemos decir que el problema es esencialmente de naturaleza alimentaria.

\subsection{El concepto jurídico de alimento}

Las ciencias jurídicas abordan los problemas sociales relacionados con los alimentos y la alimentación, fundamentalmente a partir de dos criterios; a) las obligaciones alimentarias, y b) la regulación del comercio de productos alimentarios. Estos criterios afectan considerablemente al concepto jurídico de alimento, como se verá a continuación:

a) El concepto de alimento que surge a partir de las obligaciones alimentarias revierte en una complejidad de tal naturaleza, que dificulta su definición legal. Se caracteriza por ser una "acepción extremadamente amplia que comprende a la vez la nutrición, el alojamiento y, en general, todos los bienes de consumo considerados como necesarios para la subsistencia." ${ }^{\text {"17 }}$ Es éste un criterio sobre una concepción jurídica de alimento que tiene un alcance descriptivo tal, que afecta a cosas más allá de los alimentos propiamente dichos, haciendo referencia al vestido, la educación, la vivienda, y la salud, entre otros; cuyo objeto no es garantizar la seguridad alimentaria, la inocuidad de los alimentos y/o la seguridad nutricional, sino más bien garantizar el sustento vital de personas que carecen de los medios suficientes como para proporcionárselos por sí mismas. En otras palabras, hablamos de las obligaciones que tienen determinadas personas a prestar una manutención, y del derecho que tienen otras de recibirla. Las denominaciones de esta obligaciones son diversas, pudiendo ser de dar o prestar alimentos, como lo establece el código civil español; ${ }^{18}$ o simplemente obligaciones alimentarias, como se les denomina en el ámbito del Derecho Internacional. No obstante, en lo que se refiere a la definición del concepto de alimento en el ámbito de las obligaciones alimentarias, se observa que a pesar de la prolífera producción normativa de naturaleza convencional en el ámbito del Derecho Internacional, existen grandes dificultades a la hora de llegar a consensos en cuanto a elementos básicos de cualificación, como lo es el concepto de alimento. ${ }^{19}$

La dificultad de un concepto pacífico en el ámbito de las obligaciones alimentarias, se mantienen en la actualidad, como se puede apreciar en distintos instrumentos jurídicos de carácter internacional o supranacional, como es el caso del Convenio de La Haya de 23 de noviembre de 2007 sobre Cobro Internacional de Alimentos para los Niños y otros

\footnotetext{
14 Vid. Libro Verde, "Fomentar una alimentación sana y la actividad física: una dimensión europea para la prevención del exceso de peso, la obesidad y las enfermedades crónicas”. COM (2005). Bruselas: Comisión de las Comunidades Europeas; 2005. pág. 3.

${ }^{15}$ Vid. WORLD HEALTH ORGANIZATION, et al:: Obesity: preventing and managing the global epidemic. Report of a WHO Consultation. Geneva: World Health Organization; 2000. WHO technical report series, vol. 894, pág. 133

${ }^{16}$ Vid. Dieta, O. M. S. (2003). "Nutrición y prevención de enfermedades crónicas". Informe de una Consulta Mixta de Expertos OMS/FAO. OMS, Serie de Informes Técnicos, 916. pág.24.

${ }^{17}$ BIGWOOD y GERÁRD, E. J.: Op.Cit, pág. 33.

${ }^{18}$ Vid. Artículo 142 del Código Civil español vigente en adelante.

19 Vid. Conclusiones del Abogado General Jacobs presentadas el 12 de diciembre de 1996. Antonius van den Boogaard contra Paula Laumen. - Asunto C-220/95. Argumento jurídico 38.
} 
Miembros de la Familia, el Protocolo sobre la Ley Aplicable a las Obligaciones Alimenticias, o el Reglamento $n^{\circ}$ (CE) 4/2009 relativo a la competencia, la ley aplicable, el reconocimiento y la ejecución de las resoluciones y la cooperación en materia de obligaciones de alimentos, entre otros. No obstante, se encuentran algunas referencias en lo que respecta a obligación de dar o prestar alimentos en las legislaciones nacionales, como es el caso del Código Civil español vigente, que define a los alimentos como "...todo lo que es indispensable para el sustento, habitación, vestido y asistencia médica... "20

b) El concepto de alimento que surge a partir de la necesidad de regular la producción y comercialización de productos alimentarios no es menos amplio que el concepto de alimento en materia de obligaciones alimentarias. Ciertamente, a diferencia de éstas últimas, en donde el concepto de alimento abarca cosas como la comida, el vestido, la educación, la vivienda, entre otros; el concepto jurídico de alimento que surge como una necesidad comercial está circunscrito exclusivamente a los productos alimentarios, teniéndose éstos como sinónimo de alimento. No obstante, la definición legal de estos productos; o sea, de alimento, puede llegar a comprender cosas de distinta naturaleza como los alimentos de origen natural, los ultra procesados, la goma de mascar, el agua embotellada, el tabaco, las bebidas, los cosméticos, las medicinas, todo material que entre en contacto con los alimentos, y en general cualquier sustancia destinada a ser ingerida por los seres humanos o con probabilidad razonable de serlo. Nótese pues que esta concepción jurídica propone considerar a los alimentos como un producto. En este sentido, cuando BIGWOOD y GÉRARD, de manera excepcional emprenden la ardua y solitaria tarea de intentar clarificar los objetivos y principios de un Derecho de la alimentación, encuentran ciertos elementos de motivación, entre los que señala la noción económica de los productos alimentarios, en la que entienden como producto toda mercancía destinada al consumo. En este sentido, "la noción de alimento se une a la de un acto comercial. "21

El desarrollo normativo en ambos casos transita caminos muy distintos, con objetivos y principios jurídicos también distintos, que en principio nada tienen que ver con la ESO. No obstante, a partir de las diversas crisis alimentarias sufridas en todo el planeta, causadas en parte por problemas vinculados con la producción y comercialización de productos alimentarios, ha surgido un importante interés por incluir dentro de los instrumentos jurídicos que regulan el comercio de los alimentos, normas para la protección de la salud alimentaria. En este sentido, se han realizado importantes esfuerzos de desarrollo normativo en materia de protección de la salud, cuyo objeto fundamental ha sido la higiene de los alimentos. Este desarrollo de normas de protección de la salud humana dentro del ámbito de un derecho de los alimentos aún en formación, ha sido insuficiente como para influir en el desarrollo de un concepto jurídico de alimento autónomo, más allá del ámbito comercial o doctrinal; pero al mismo tiempo supone el germen a partir del cual se vislumbra la evolución de la legislación alimentaria hacia un verdadero Derecho de los alimentos autónomo. En este sentido, el carácter alimentario de la crisis de la ESO, el papel de la industria alimentaria, y la relación que puede existir entre el consumo de productos alimentarios energéticamente densos y nutricionalmente pobres y la ESO, conlleva a considerar el concepto jurídico de alimento como producto-mercancía.

${ }^{20}$ Artículo 144 del Código Civil español
${ }^{21}$ Cfr. BIGWOOD y GERÁRD, Op. Cit, pág. 34.

Revista de Direito Brasileira | São Paulo, SP | v. 18 | n. 7 | p. 463 - 503 |Set./Dez. 2017 
Alimento es una palabra polisémica que fundamentalmente hace referencia a las sustancias que los seres vivos necesitan para su sustento. ${ }^{22}$ Interesa el significado vulgar del término alimento ${ }^{23}$, desde el punto de vista del uso que común y mayoritariamente que las personas hacen del mismo a la hora de comunicarse y de relacionarse entre sí.

Para una primera aproximación del significado vulgar de alimento se ha consultado el diccionario de la Real Academia Española (RAE). Los criterios de "vigencia, de extensión y de frecuencia en el uso general culto" que la RAE utiliza para incluir un término en su diccionario y ofrecer su significado, ${ }^{24}$ hace de ésta una herramienta eficaz y fiable a la hora de medir de forma bastante aproximada de qué manera las personas utilizan y entienden los vocablos cuando éstas se comunican y se relacionan entre sí.

En este sentido, al consultar la palabra alimento en el diccionario de la RAE, se pueden encontrar varios significados. ${ }^{25}$ De todas las definiciones que ofrece, aquella que se puede considerar más acertada desde el punto de vista del uso vulgar del término es "Poder nutritivo o capacidad para nutrir de una sustancia comestible." 26 Esto quiere decir, que en general cuando las personas usan la palabra alimento, ${ }^{27}$ habitualmente se refieren a una sustancia comestible que tiene el poder y la capacidad de nutrir.

Otra fuente a considerar para la aproximación de un concepto no legal ni científico de alimento proviene de la Organización de las Naciones Unidas para la Alimentación y la Agricultura (FAO). Por el grado de especialización y autoridad de una organización como la FAO, su definición no jurídica de alimento sirve de referencia fiable, para contrastar la definición que ofrece la RAE. Al consultar el glosario de términos que está disponible en la web de la FAO, se ha encontrado la siguiente definición de alimento: "producto natural o elaborado susceptible de ser ingerido y digerido, cuyas características lo hacen apto y agradable al consumo, constituido por una mezcla de nutrientes que cumplen determinadas funciones en el organismo. ,28

A partir de esta definición, si se quiere informal, que no obstante ofrece la FAO, se observa que el significado de la RAE es uno de los más completos en relación con otros diccionarios consultados. ${ }^{29}$ En este sentido, si se reconoce que los criterios de la RAE para la

\footnotetext{
${ }^{22}$ También puede se usa en sentido metafórico, "aquello de lo que se sirven las cosas sin vida para su existencia." Véase acepción 4 de la definición de alimento del Diccionario de la Lengua Española, disponible en http://dle.rae.es/?id=1rm36tt Accedido el 03 de marzo de 2015.

${ }^{23}$ Por vulgar debe entenderse como lo "dicho de una lengua: que se habla actualmente, por contraposición a las lenguas sabias.” Vid. (http://dle.rae.es/?id=c5Ns9tE|c5O7ZCI, consultado el 10 de marzo de 2016).

${ }^{24}$ Disponible en http://www.rae.es/diccionario-panhispanico-de-dudas/que-es. Accedido el 02 de marzo de 2015.

${ }^{25}$ Alimento: Del lat. alimentum, der. de alěre 'alimentar'. 1. m. Conjunto de sustancias que los seres vivos comen o beben para subsistir. 2. m. Cada una de las sustancias que un ser vivo toma o recibe para su nutrición. 3. m. Poder nutritivo o capacidad para nutrir de una sustancia comestible. La leche tiene mucho alimento. Es una bebida de poco alimento. 4. m. Cosa que sirve para mantener la existencia de algo que, como el fuego, necesita de pábulo. $5 . \mathrm{m}$. Sostén, fomento, pábulo de cosas incorpóreas, como virtudes, vicios, pasiones, sentimientos y afectos del alma. 6 . m. pl. Der. Prestación debida entre parientes próximos cuando quien la recibe no tiene la posibilidad de subvenir a sus necesidades. Disponible en http:// dle.rae.es/? id=1rm36tt. Accedido el 03 de marzo de 2015.

${ }^{26}$ Disponible en http://dle.rae.es/?id=1rm36tt. Accedido el 03 de marzo de 2015.

${ }^{27}$ Se hace referencia a las personas de habla hispana.

${ }^{28}$ Cfr. http://www.fao.org/docrep/014/am401s/am401s07.pdf. Accedido el 01 de marzo de 2016.

${ }^{29} \mathrm{Al}$ consultar el término alimento en otros diccionarios, se han encontrado los siguientes significados: Diccionario del diario El Mundo: "Cualquier sustancia que toma o recibe un ser vivo para su nutrición: alimento sólido y líquido."

(http://diccionarios.elmundo.es/diccionarios/cgi/diccionario/lee_diccionario.html?busca=alimento\&diccionario=1\&s ubmit=Buscar+, consultado el día 01 de marzo de 2016). Diccionario del diario El País: "Sustancia que toma un organismo o ser vivo para obtener la materia y la energía necesarias para la vida." (http://servicios.elpais.com/diccionarios/castellano/alimento, consultado el día 01 de marzo de 2016) Enciclopedia Espasa: "Sustancia que proporciona a los seres vivos los nutrientes necesarios para su crecimiento y subsistencia." (http://espasa.planetasaber.com/search/results.asp?txt=alimento, consultado el día 01 de marzo de 2016), Diccionario Larousse: "Sustancia bruta o transformada que sirve para nutrirse". Gran diccionario de uso del español actual:
}

Revista de Direito Brasileira | São Paulo, SP | v. 18 | n. 7 | p. 463 - 503 | Set./Dez. 2017 
inclusión y significación de términos en su diccionario, son un reflejo fiel del uso vivo y mayoritario del léxico de los hispanohablantes; y asimismo se reconoce un alto nivel de coincidencia entre las definiciones de la RAE y la FAO que hemos analizado, se puede afirmar que las personas tienen una concepción del significado de alimento como una sustancia comestible que nutre.

Por su parte la ciencia contribuye a la definición del significado de alimento de forma clara y objetiva. Con perspectiva multidisciplinar, se pretende abandonar el enfoque jurídico transversal que cohesione las peresentes reflexiones que especialmente toman en consideración las aportaciones que hacen la Bromatología, la Nutrición, la Dietética, y la Nutriología, al considerar que el objeto de estudio central de éstas son los alimentos y los procesos biológicos que se producen en torno a éstos, excluyendo al resto de disciplinas como la biología, la química, la agronomía, entre otras, cuyos aportes en conjunto se consideran como fuentes para la construcción de un concepto fisiológico de alimento.

Desde el punto de vista de la bromatología, alimento se define como "un producto, natural o transformado, capaz de suministrar al organismo que lo ingiere la energía y las estructuras químicas necesarias para que pueda desarrollar sin problemas sus procesos biológicos." 30 Por su parte, la Nutriología, como rama de la medicina especializada en la alimentación humana, define a los alimentos como "órganos, tejidos o secreciones de organismos de otras especies que contienen concentraciones apreciables de uno o más nutrimentos biodisponibles, cuya ingestión en las cantidades y formas habituales es inocua...",31 Por otro lado, la Nutrición y la Dietética entendidas como define a los alimentos como "todo aquel producto o sustancia que, ingerido, aporta materiales asimilables que cumplen una función nutritiva en el organismo." 32

Así pues las definiciones que ofrecen tanto la Bromatología, como la Nutriología y la Nutrición y Dietética, resulta que la propiedad nutritiva de los alimentos adquiere una certeza dogmática entre todas las disciplinas científicas, que resulta imposible de desvincular del concepto de alimento, y que coincide también, con la percepción que tienen las personas.

La alimentación es una cuestión universal, por ello importa un concepto jurídico que supere el aspecto subjetivo, dificultad que aumenta si se toma en cuenta su tendencia a la mutabilidad en el tiempo y en el espacio. La concreción conceptual de alimento puede encontrar satisfacción en el análisis del derecho convencional en el ámbito internacional.

Encontramos pues que el Codex Alimentarius define a los alimentos como:

“...toda sustancia, elaborada, semielaborada o bruta, que se destina al consumo humano, incluyendo las bebidas, el chicle y cualesquiera otras sustancias que se utilicen en la fabricación, preparación o tratamiento de los alimentos, pero no incluye los cosméticos ni el tabaco ni las sustancias utilizadas solamente como medicamentos." 33

El Codex forma parte del Acuerdo sobre la Aplicación de Medidas Sanitarias y

\footnotetext{
"Nombre genérico aplicado a las distintas sustancias que se dan a los seres vivos o que éstos consumen para subsistir físicamente". Nótese que en la mayoría de las consultas arriba citadas, implícita o explícitamente al definir alimento éste está siempre vinculado con la nutrición, pero en ninguno en los diccionarios consultados, excepto el de la RAE y en el glosario de la FAO, se hace referencia a que puedan ser comestibles.

30. GUTIERREZ. Op Cit. Pág. 21.

${ }^{31}$ Cfr. CASANUEVA, Esther; PEREZ, Ana Bertha; KAUFER, Martha. Nutriologia medica/Medical Nutriologia. Ed. Médica Panamericana, 2008. Pág.479.

${ }^{32}$ Cfr. PICASSO, Rafael Repullo: Nutrición humana y dietética: la alimentación en la salud y en la enfermedad. Marbán, 2001. Pág. 11.

${ }^{33}$ Vid. Codex Alimentariuus. (2011). Comisión del Codex Alimentarius . Manual de Procedimiento. pág. 22. Disponible en ftp://ftpág.fao.org/codex/Publications/ProcManuals/Manual_20s.pdf. Accedido el 06 de noviembre de 2015.
} 
Fitosanitarias (Acuerdo MSF), en este sentido; las normas del Codex Alimentarius “...se han convertido, de hecho, en las normas internacionales que regulan los productos alimentarios objeto de intercambios comerciales internacionales y, en gran medida, en elemento de referencia para la legislación nacional sobre inocuidad de los alimento;" 34 por lo que su normas tienen alcance global en el ámbito del comercio internacional, afectado a los países que formen parte de la Organización Mundial del Comercio (OMC), y son de gran influencia en las legislaciones nacionales. En la definición de alimento del Codex se observa que se incluyen listas positivas y negativas indicando qué puede y qué no puede considerarse alimento, aunque no incluye ninguna mención sobre el carácter nutritivo que debe tener un alimento. Por su parte sin embargo, en un informe del Consejo europeo del Codex Alimentarius Europaeus de 1958, se definía el concepto de alimento incluyendo la mención a que deben satisfacer las necesidades nutricionales de los seres humanos. ${ }^{35}$

En el caso de la legislación europea, el artículo 2 del Reglamento (CE) no 178/2002 del Parlamento Europeo y del Consejo de 28 de enero de 2002 por el que se establecen los principios y los requisitos generales de la legislación alimentaria (Reglamento $n^{\circ}$ 178/2002), define a los alimentos o productos alimenticios como:

"A efectos del presente Reglamento, se entenderá por «alimento» (o «producto alimenticio») cualquier sustancia o producto destinados a ser ingeridos por los seres humanos o con probabilidad razonable de serlo, tanto si han sido transformados entera o parcialmente como si no. «Alimento» incluye las bebidas, la goma de mascar y cualquier sustancia, incluida el agua, incorporada voluntariamente al alimento durante su fabricación, preparación o tratamiento. Se incluirá el agua después del punto de cumplimiento definido en el artículo 6 de la Directiva 98/83/CE y sin perjuicio de los requisitos estipulados en las Directivas 80/778/CEE y 98/83/CE.

«Alimento» no incluye: a) los piensos; b) los animales vivos, salvo que estén preparados para ser comercializados para consumo humano; c) las plantas antes de la cosecha; d) los medicamentos tal y como lo definen las Directivas 65/65/CEE y 92/73/CEE del Consejo; e) los cosméticos tal como los define la Directiva 76/768/CEE del Consejo; f) el tabaco y los productos del tabaco tal como los define la Directiva 89/622/CEE del Consejo; g) las sustancias estupefacientes o psicotrópicas tal como las define la Convención Única de las Naciones Unidas sobre Estupefacientes, de 1961, y el Convenio de las Naciones Unidas sobre Sustancias Psicotrópicas, de 1971; h) los residuos y contaminantes."

De forma similar a la definición del Codex Alimentarius, el artículo 2 del Reglamento $\mathrm{n}^{\circ}$ 178/2002 también hace referencia a una lista positiva y negativa de lo que debe considerarse como alimento y lo que no. Coincide también con el Codex en que no se requiere que estos productos tengan la cualidad de nutrir.

En el análisis conceptual se han encontrado fundamentalmente cuatro problemas en torno al concepto jurídico de alimento: a) los alimentos se conciben como un productomercancía; b) la exclusión de la propiedad nutricional como cualidad esencial; c) su carácter ilegítimo e irracional; y d) la dificultad de proponer un concepto universal.

a) Los alimentos se conciben como un producto-mercancía: Conlleva a priori la exclusión del aspecto social de los alimentos, privilegiando el aspecto económico. Los aspectos

\footnotetext{
${ }^{34}$ Disponible en http://www.who.int/foodsafety/areas_work/food-standard/general_info/es/index2.html. Accedido el 15 de enero de 2016.

${ }^{35}$ BIGGWOOD: Op. Cit, pág. 123.
}

Revista de Direito Brasileira | São Paulo, SP | v. 18 | n. 7 | p. 463 - 503 | Set./Dez. 2017 
sociales y económicos, son considerados como elementos institucionales que orientan y condicionan la elaboración de leyes y de los Reglamentos, en este caso que regulan los procesos de producción, distribución y comercialización de los productos alimentarios. ${ }^{36}$ Por otro lado, al definir a los alimentos como un producto, implica equiparar diversas sustancias o cosas con los alimentos, como una misma cosa. Entendemos que deber haber una denominación legal de las distintas sustancias que abarca el concepto de producto alimentario. Particularmente necesario es la clarificación entre productos ultra procesados y los alimentos. Tal necesidad obedece a que los alimentos y productos ultra procesados siendo iguales en apariencia, son nutricionalmente muy diferentes. Los productos ultra procesados presentan ciertas características negativas, además de las nutricionales, que no presentan los alimentos y que se relacionan con las causas de la ESO. BIGWOOD y GÉRARD, al analizar los elementos de cualificación de los fundamentos de un Derecho de la alimentación, hacen mención a unas nociones particulares con respecto al concepto general de alimento, en las que incluye la noción del alimento natural como oposición de los alimentos de preparación sintética. ${ }^{37}$ Se refieren a estos alimentos de preparación sintética como productos artificiales y no tradicionales, pronunciándose a favor de éstos, en previsión de un futuro en el que la supervivencia del ser humano por la presión demográfica los hará necesarios. BIGWOOD y GÉRARD no se refieren expresamente a los productos ultra procesados, cuando hablan de los alimentos de preparación sintética, probablemente porque entonces los productos ultra procesados no se conocían con este nombre. En todo caso, parecen acertar en la noción de productos alimentarios artificiales, coincidiendo con otros autores actuales como MONTEIRO. ${ }^{38}$

b) La exclusión de la propiedad nutricional como cualidad esencial: En la concepción vulgar y científica de alimento, hemos podido confirmar que la característica esencial que define a los alimentos es su capacidad de nutrir. Tanto el Codex Alimentarius, como el Reglamento (CE) $n^{\circ} 178 / 2002$, no toman en cuenta esta característica esencial de nutrir. Por lo tanto, es posible considerar alimento a sustancias o productos, que, si bien sí son alimentarios, no son alimenticios; es decir no nutren. Es el caso de los productos ultra procesados, los cuales son nutricionalmente pobres y energéticamente densos. Si entendemos que alimento es toda sustancia que nutre, muy probablemente la mayoría de los productos ultra procesados no serían considerados alimentos sino simplemente productos sintéticos consumibles.

c) Su carácter legítimo: Entendemos que las normas jurídicas en su función de regular los hechos sociales, no pueden apartarse de esa realidad social. Vemos pues como una parte de la sociedad, la que se dedica a la producción, distribución y comercialización de productos alimentarios, concibe a los alimentos como un producto-mercancía. Asimismo, la otra parte de la sociedad representada por los consumidores alimentarios y la ciencia que entienden a los alimentos como sustancias cuya principal propiedad es nutrir.

d) La dificultad de proponer un concepto universal: Esta dificultad supone en principio superar las divergencias propias de las distintas legislaciones nacionales en materia alimentaria. Se puede superar por la necesidad de armonizar las regulaciones de los intercambios comerciales entre Estados, deduciéndose de los planteamientos de BIGWOOG y GÉRARD de hace casi medio siglo, que efectivamente el crecimiento

\footnotetext{
${ }^{36}$ Vid. BIGWOOD y GÉRARD, Op. Cit., pág. 67.

37 Ibídem.,. pág 34.

${ }^{38}$ Vid. MONTEIRO CA, CANNON G, LEVY RB et al.: "NOVA. The star shines bright. [Food classification. Public health]" World Nutrition January-March 2016, 7, 1-3, pág.32.
}

Revista de Direito Brasileira | São Paulo, SP | v. 18 | n. 7 | p. 463 - 503 |Set./Dez. 2017 
espectacular del comercio internacional, es por sí mismo un factor unificador o de aproximación de las legislaciones nacionales, cuya explicación se debe "a una unidad natural de derecho en el dominio de las relaciones económicas internacionales. Partiendo del principio según el cual la economía de los Estados está condicionada por un ius commune commercium." 39

\subsection{El concepto de salud alimentaria}

Las normas sobre la producción, comercialización y distribución de productos alimentarios tradicionalmente se han ajustado a las necesidades propias del comercio de productos alimentarios, atendiendo de forma secundaria aspectos de prevención o contención de situaciones que atenten contra la salud pública. ${ }^{40}$. No obstante, se observa que dentro de los sistemas normativos que se encargan de regular el comercio de los productos alimentarios, ha venido surgiendo en los últimos años, un tipo de norma que tiene un objeto claramente diferenciado al interés comercial, ubicándose en el ámbito de la protección de la salud humana. El objeto de estas nuevas normas se reúne en torno a la protección de la salud alimentaria de las personas.

Para nosotros, la salud alimentaria abarca tres dimensiones de la alimentación humana, que requieren ser satisfechas para alcanzar un estado de completo bienestar físico, mental y social. ${ }^{41}$ A saber; el acceso físico y económico a suficientes alimentos por parte de la población (seguridad alimentaria); la higiene e inocuidad de los productos alimentarios (inocuidad de los alimentos); y la calidad nutricional de los productos alimentarios (seguridad nutricional).

\subsubsection{La seguridad alimentaria}

La seguridad alimentaria o "Food Security" en inglés, es el término que se usa para señalar el estado en el cual existe suficiente disposición y/o accesibilidad a los alimentos para satisfacer las necesidades nutricionales de la población. Por el contrario, existe inseguridad alimentaria o "Food insecurity" cuando no hay alimentos suficientes para satisfacer las necesidades alimenticias de la población, concepto que está asociado directamente con el hambre y la desnutrición. Estos términos guardan relación, con la dimensión de la crisis global por malnutrición relacionada con el problema del hambre en el mundo.

La Declaración de Roma sobre la seguridad alimentaria mundial, surgida a partir de la Cumbre Mundial sobre la Alimentación de 1996, hace referencia a este problema. No define el concepto de seguridad alimentaria, pero claramente se refiere a ella como los alimentos suficientes para satisfacer las necesidades nutricionales básicas de las personas. El Plan de Acción de la Cumbre, sin embargo, va más allá de ofrecer un concepto abstracto, prefiriendo utilizar una estructura lingüística descriptiva de un hecho consumado al declarar que,

"existe seguridad alimentaria cuando todas las personas tienen en todo momento acceso físico y económico a suficientes alimentos inocuos y nutritivos para satisfacer sus necesidades alimenticias y sus preferencias en cuanto a los alimentos a fin de llevar una vida activa y sana."

\footnotetext{
${ }^{39}$ Cfr. BIGWOOD y GÉRARD, Op.Cit., pág 17.

${ }^{40}$ Vid. BIGWOOD y GÉRARD, Op.Cit .Pág 4.

41 Vid. Preámbulo de la Constitución de la Organización Mundial de la salud. Disponible en http://apps.who.int/gb/bd/PDF/bd48/basic-documents-48th-edition-spág.pdf\#page=7. Accedido el 12 de abril de 2015.

42 Cfr. Declaración de Roma sobre la seguridad alimentaria mundial y Plan de acción de 1996. http://www.fao.org/docrep/003/w3613s/w3613s00.HTM, consultado el 11 de abril de 2016.
}

Revista de Direito Brasileira | São Paulo, SP | v. 18 | n. 7 | p. 463 - 503 | Set./Dez. 2017 
Esta descripción va más allá del concepto de seguridad alimentaria, puesto que su noción en stricto sensu, gira en torno a la idea del acceso físico y económico a suficientes alimentos. Las menciones a la inocuidad alimentaria y la seguridad nutricional, son ciertamente dos de las dimensiones de la salud alimentaria; aunque cada una conserva su propia entidad y dinámica. La primeria dimensión de la salud alimentaria está vinculada fundamentalmente, en su fase más primaria, a la actividad agropecuaria. Por tanto, la actividad normativa de esta primera fase, se caracteriza por ser uno de los instrumentos por el cual se ejecutan políticas de producción agrícola y pecuaria, como por ejemplo la Política Agraria Común Europea (PAC). La actividad agropecuaria es la fuente de los productos alimenticios, que cuando no están sometidos a procesos de refinamiento o incorporadas a los productos alimentarios ultraprocesados, se mantienen nutricionalmente equilibrados; por lo que no requieren en principio una regulación especial que garantice la calidad nutricional de estos alimentos. ${ }^{43}$ En cuanto a las otras dos dimensiones de la salud alimentaria, se observa que partir del desarrollo de la agroindustria y de la aparición de los distintos productos alimentarios, entre los que se encuentran productos alimenticios con distinto grado de procesamiento y los productos ultra procesados, surgen problemas de inocuidad y calidad nutricional. Por tanto, la definición del término seguridad alimentaria nutricional, enunciado por la FAO, expresa en realidad una noción del concepto de salud alimentaria:

"la Seguridad Alimentaria Nutricional "es un estado en el cual todas las personas gozan, en forma oportuna y permanente, de acceso físico, económico y social a los alimentos que necesitan, en cantidad y calidad, para su adecuado consumo y utilización biológica, garantizándoles un estado de bienestar general que coadyuve al logro de su desarrollo."44

\subsubsection{La inocuidad de los alimentos}

La inocuidad alimentaria o "food safety" tiene que ver con los procedimientos y acciones que se lleven a cabo con el objeto de garantizar la seguridad y la higiene de los alimentos. En concreto, la inocuidad alimentaria se refiere a "la garantía de que los alimentos no causarán daño al consumidor cuando se preparen y/o consuman de acuerdo con el uso a que se destinan." 45

En el Codex Alimentarius se establece los principios de aplicación práctica para el análisis de riesgo, relacionado con la inocuidad de los alimentos. Éstos se basan en un proceso que consta de tres componentes: evaluación de riesgos, gestión de riesgos y comunicación de riesgos. Dentro de los complejos procesos relacionados con este sistema de análisis del riesgo establecido en el Codex Alimentarius, ${ }^{46}$ destaca el de la evaluación de riesgos, el cual se

\footnotetext{
${ }^{43}$ No obstante, ante el avance de la biotecnología y la producción de organismos modificados geneticamente, ha aparecido directrices de la Comisión del Codex Alimentarius que abordan esta nuevas situaciones, desde los sistemas de análisis del riesgo relacionadas con la inocuidad (véase la OMS, FAO. Garantía de la inocuidad y calidad de los alimentos: directrices para el fortalecimiento de los sistemas nacionales de control de los alimentos. 2003, pág. 72. Disponible en ftp://ftpág.fao.org/docrep/fao/006/y8705s/y8705s00.pdf. Accedido el 12 de abril de 2016), así como también sistemas de análisis del riesgo nutricional (véase ALIMENTARIUS, CODEX. Comisión del Codex Alimentarius . Manual de Procedimiento. 2011. pág. 155)

${ }^{44}$ Cfr. DE LOMA-OSSORIO, E.: Seguridad Alimentaria y Nutricional. Conceptos Básicos. Programa Especial para la Seguridad Alimentaria-PESA-Centroamérica, Ministerio de Asuntos Exteriores de Cooperación. Agencia Española de Cooperación Internacional. FAO. 2007. Pág.2.

${ }^{45}$ Cfr. Codex Alimentarius, Código internacional recomendado de prácticas. Principios generales de higiene de los alimentos. cac/rcp-1 (1969), Rev. 3 (1997), enmendado en 1999. pág. 9. Disponible en http://www.fao.org/ag/agn/cdfruits_es/others/docs/CAC-RCP1-1969.PDF. Accedido 21 de mayo de 2015.

46 Vid. Codex Alimentariuus. (2011). Comisión del Codex Alimentarius. Manual de Procedimiento. pág. 119. Disponible en ftp://ftpág.fao.org/codex/Publications/ProcManuals/Manual_20s.pdf. Accedido el 06 de noviembre de 2015.
} 
caracteriza por estar basado en conocimientos científicos, sobre la base de los cuales se determina, entre otras cuestiones, el peligro relacionados con la inocuidad, el cual se define como "un agente biológico, químico o físico presente en el alimento, o bien la condición en que éste se halla, que puede causar un efecto adverso para la salud."47

De los peligros biológicos que se pueden encontrar en productos alimentarios contaminados destacan las bacterias (como la Salmonella, Campylobacter, Escherichia coli enterohemorrágica), los virus (hepatitis A), parásitos (trematodos, echinococcus spp o Taenia solium, ascaris, Cryptosporidium, Entamoeba histolytica o Giardi) o priones (agentes infecciosos constituidos por proteínas que se caracterizan por estar asociados a determinados tipos de enfermedades neurodegenerativas como la Encefalopatía Espongiforme Bovina (EBB). ${ }^{48}$

Entre los peligros químicos las sustancias que más plantean problemas para la salud son las toxinas naturales y los contaminantes. Las toxinas naturales abarcan las micotoxinas, las biotoxinas marinas, los glucósidos cianogénicos y las toxinas presentes en las setas venenosas; los contaminantes orgánicos persistentes, como las dioxinas y los bifenilos policlorados; y los metales pesados como el plomo, el cadmio y el mercurio que producen patologías neurológicas y renales. $^{49}$

En cuanto a los peligros físicos "se asocian con objetos extraños, tales como pedazos de metal o vidrio, en alimentos". 50

La inocuidad alimentaria suele estar asociada con el término calidad de los alimentos, entendida éste como los "atributos que influyen en el valor de un producto para el consumidor;", 51 se excluye por tanto toda relación entre calidad de los productos alimentarios con la cualidad nutricional de éstos. No encontramos afortunado el término calidad alimentaria, cuando ésta no se vincula con la cualidad nutricional de los productos alimentarios. Hacer depender la noción de calidad alimentaria con los criterios subjetivos y mutables de los consumidores; lo que implica que la calidad alimentaria obedezca a criterios de marketing, que pueden no ser compatibles con la protección de la salud pública. Ligar calidad alimentaria, con la cualidad nutricional de los productos alimentarios, es un criterio objetivo que además está en sintonía con el espíritu de las normas del ámbito de la salud alimentaria.

No obstante, para la legislación alimentaria internacional resulta relevante la distinción entre la inocuidad de los alimentos y la calidad de los alimentos;

"Los términos inocuidad de los alimentos y calidad de los alimentos pueden inducir a engaño. Cuando se habla de inocuidad de los alimentos se hace referencia a todos los riesgos, sean crónicos o agudos, que pueden hacer que los alimentos sean nocivos para la salud del consumidor. Se trata de un objetivo que no es negociable. El concepto de calidad abarca todos los demás atributos que influyen en el valor de un producto para el consumidor. Engloba, por lo tanto, atributos negativos, como estado de descomposición, contaminación con suciedad, decoloración y olores desagradables, pero también atributos positivos, como origen, color, aroma, textura y métodos de elaboración de los alimentos. Esta distinción entre inocuidad y calidad tiene repercusiones en las políticas

\footnotetext{
${ }^{47}$ Cfr. Codex Alimentarius, Código internacional recomendado de prácticas. Principios generales de higiene de los alimentos. cac/rcp-1 (1969), Rev. 3 (1997), enmendado en 1999. pág. 10. Disponible en http://www.fao.org/ag/agn/cdfruits_es/others/docs/CAC-RCP1-1969.PDF. Accedido el 21 de mayo de 2015.

${ }^{48}$ Vid. http://www.who.int/mediacentre/factsheets/fs399/es/ Consultada el 12/04/16.

${ }^{49}$ Ibídem.

${ }^{50}$ Cfr. Programa Conjunto FAO/OMS sobre normas alimentarias. Comité del Codex sobre higiene de los alimentos. Trigésima-cuarta reunión, Bangkok, Tailandia, 8 - 13, Octubre de 2001. pág.2.

${ }^{51}$ Cfr. OMS, FAO. Garantía de la inocuidad y calidad de los alimentos: directrices para el fortalecimiento de los sistemas nacionales de control de los alimentos. 2003. pág. 4. Disponible en ftp://ftpág.fao.org/docrep/fao/006/y8705s/y8705s00.pdf. Accedido el 12 de abril de 2016.
}

Revista de Direito Brasileira | São Paulo, SP | v. 18 | n. 7 | p. 463 - 503 | Set./Dez. 2017 
públicas e influye en la naturaleza y contenido del sistema de control de los alimentos más indicado para alcanzar objetivos nacionales predeterminados.",52

Las repercusiones en las políticas públicas que influyen en la naturaleza y contenido del sistema de control de los alimentos, a los que se hace referencia son estrictamente de naturaleza comercial. El creciente aumento del comercio internacional de productos alimentarios, cada vez más liberalizado, exige la erradicación de obstáculos y barreras comerciales innecesarios. La salud pública es una de las causas que justifican la implementación de medidas nacionales que limite el comercio de productos alimentarios. Por tanto, la inocuidad de los alimentos se incluye dentro de esas medidas restrictivas al comercio, en ocasión a la protección de la salud pública, siempre y cuando esté suficientemente justificado su aplicación. En este sentido, en el ámbito del comercio internacional de alimentos conviene distinguir entre inocuidad alimentaria y la mal llamada calidad alimentaria. Los problemas con la inocuidad de los productos alimentarios afectan a la salud de los consumidores alimentarios, mientras que los problemas relacionados con la calidad alimentaria no. ${ }^{53}$

\subsubsection{La seguridad nutricional}

Además de las normas que tienden a garantizar la seguridad alimentaria y la inocuidad de los alimentos, existen normas, dentro del ámbito de la protección de la salud alimentaria, que tienen por objeto garantizar la seguridad nutricional de los productos alimentarios. Se observa que este tipo de normas alimentarias son las menos comunes, a pesar de que su objeto implica una elevada evolución de las relaciones que se producen a partir del hecho alimentario. Suponen el colmo de la satisfacción de las necesidades alimentarias más allá de la disposición suficiente de alimentos inocuos.

La seguridad nutricional se constituye pues como el tercero de los aspectos a proteger dentro de la salud alimentaria, y se refiere a la ausencia de riesgos nutricionales en los productos alimentarios, que puedan causar daño en la salud de las personas.

El Código Internacional Recomendado de Prácticas CAC/RCP-1 (1969), en el que se establecen los principios generales de higiene de los alimentos, no considera la existencia de agentes nutricionales como factor de peligro. El sistema de análisis del riesgo, a la hora de la determinación del riesgo de relacionado con la inocuidad de los productos alimentarios sólo establece como factor de peligro a agentes biológicos, químicos y físicos. No obstante, en el manual de procedimiento del Codex Alimentarius, se encuentran establecidos los principios de análisis de riesgos nutricionales y las directrices para su aplicación, que complementa el sistema de análisis del riesgo establecido para la inocuidad alimentaria; tal como se señala en el propio manual cuando dice que:

"Con la referencia a los aspectos relacionados con la salud, además de a la inocuidad de los alimentos, se pretende señalar de modo más claro que el análisis de riesgos se debe aplicar a las cuestiones nutricionales comprendidas

\footnotetext{
${ }^{52}$ Cfr. OMS, FAO. Garantía de la inocuidad y calidad de los alimentos: directrices para el fortalecimiento de los sistemas nacionales de control de los alimentos. 2003. pág. 4. Disponible en ftp://ftpág.fao.org/docrep/fao/006/y8705s/y8705s00.pdf. Accedido el 12 de abril de 2016.

${ }^{53}$ Vid. OMS, FAO. Garantía de la inocuidad y calidad de los alimentos: directrices para el fortalecimiento de los sistemas nacionales de control de los alimentos. 2003. pág. $6 . \quad$ Disponible en ftp://ftpág.fao.org/docrep/fao/006/y8705s/y8705s00.pdf. Accedido el 12 de abril de 2016.
} 

en el mandato de la Comisión del Codex Alimentarius y de sus órganos
auxiliares. 54

El mandato a que hace alusión la cita anterior consiste, según el art. 1 de los estatutos de la comisión del Codex, en proteger la salud de los consumidores. Al igual que con la inocuidad alimentaria, el sistema de análisis del riesgo nutricional, es un proceso que consta de tres componentes; la evaluación de riesgos nutricionales; la gestión de riesgos nutricionales; y la comunicación de riesgos nutricionales, ${ }^{55}$ y "hace referencia a los nutrientes y las sustancias afines y a los riesgos para la salud resultantes de una ingesta insuficiente o excesiva."56 Se define el riesgo nutricional como:

"Función de la probabilidad de un efecto nocivo para la salud derivado de la ingesta insuficiente o excesiva de un nutriente o una sustancia afín y de la gravedad de dicho efecto, como consecuencia de un peligro o peligros asociados a los nutrientes presentes en los alimentos. ${ }^{, 57}$

Nótese que esta definición de riesgo nutricional hace mención a las dos dimensiones de los problemas de malnutrición. La falta de nutrientes, relacionado con la inseguridad alimentaria; y la ingesta excesiva de un nutriente o una sustancia afín, que es lo que ocurre con la ESO. Esta definición de riesgo nutricional se completa al incluir la definición de efecto nocivo de la salud:

"Alteración de la morfología, la fisiología, el crecimiento, el desarrollo, la reproducción o la duración de la vida de un organismo, sistema, población o subpoblación que da lugar a un deterioro de la capacidad funcional, un deterioro de la capacidad de compensación del estrés adicional o una mayor vulnerabilidad a otras influencias." ${ }^{, 58}$

Ambas definiciones se adaptan perfectamente a las situaciones que están presente en la ESO; ingesta excesiva de una sustancia alimentaria cuyo efecto nocivo en la salud se traduce una alteración de la morfología, fisiología, desarrollo y duración de la vida de las personas. No obstante, no cabe duda de las consecuencias positivas en la lucha contra la ESO, de implementarse en las legislaciones nacionales.

En lo que respecta a la Unión Europes (UE), se observan importantes evidencias que indican la escasa importancia que tiene la seguridad nutricional de los productos alimentarios en la legislación y la política alimentaria:

a) La definición del concepto jurídico de alimento, establecido en el artículo 2 del Reglamento $\mathrm{n}^{\circ} 178 / 2002$, no incluye la propiedad nutritiva como una característica

54 Cfr. Codex Alimentariuus (2011). Comisión del Codex Alimentarius. Manual de Procedimiento. pág. 155. Disponible en ftp://ftpág.fao.org/codex/Publications/ProcManuals/Manual_20s.pdf. Accedido el 06 de noviembre de 2015.

55 Vid. Codex Alimentariuus (2011). Comisión del Codex Alimentarius . Manual de Procedimiento. pág. 160. Disponible en ftp://ftpág.fao.org/codex/Publications/ProcManuals/Manual_20s.pdf. Accedido el 06 de noviembre de 2015.

${ }^{56}$ Cfr. Codex Alimentariuus (2011). Comisión del Codex Alimentarius . Manual de Procedimiento. pág. 156. Disponible en ftp://ftpág.fao.org/codex/Publications/ProcManuals/Manual_20s.pdf. Accedido el 06 de noviembre de 2015.

${ }^{5}$ Cfr. Codex Alimentariuus (2011). Comisión del Codex Alimentarius . Manual de Procedimiento. pág. 158. Disponible en ftp://ftpág.fao.org/codex/Publications/ProcManuals/Manual_20s.pdf. Accedido el 06 de noviembre de 2015.

${ }^{58}$ Cfr. Codex Alimentariuus (2011). Comisión del Codex Alimentarius . Manual de Procedimiento. pág. 158. Disponible en ftp://ftpág.fao.org/codex/Publications/ProcManuals/Manual_20s.pdf. Accedido el 06 de noviembre de 2015 . 
imprescindible para que cualquier sustancia o producto pueda considerarse legalmente alimento.

b) A pesar de las recomendaciones hechas por la comisión del Codex Alimentarius en torno a la inclusión del riesgo nutricional en el sistema de análisis de riesgo, de los dictámenes de la EFSA en relación las cantidades de azúcar de ingesta diaria recomendada o los efectos nocivos para la salud de los AGT, o que el propio Reglamento $n^{\circ}$ 178/2002 reconoce la existencia de riesgos nutricionales, en la práctica no existe ningún tipo de repercusión en la política alimentaria, en la regulación, o en la reformulación de los productos alimentarios con características nutricionales negativas.

c) Aunque no existe formalmente una política alimentaria más allá de la PAC (cuyo objeto es garantizar la seguridad alimentaria), sí existe una política alimentaria de hecho que consiste en garantizar la inocuidad de los alimentos y la libre circulación de productos alimentarios; en ambos casos con un importante desarrollo normativo. No ocurre lo mismo en cuanto a la seguridad nutricional.

d) En el Derecho de la UE no se vincula el concepto de calidad alimentaria, con la cualidad nutricional de los productos alimentarios.

e) La UE no incorpora en su legislación las recomendaciones de la OMS en cuanto a la ingesta diaria de referencia de sodio y azúcar, en el etiquetado nutricional.

f) La UE no prohíbe, limita u obliga a informar sobre el uso de los ácidos grasos trans (AGT) en los productos alimentarios. Pese que la OMS recomienda eliminarlos de la cadena alimentaria por considerarlos un factor de peligro para la salud.

g) La mayoría de los instrumentos jurídicos que tienen por objeto la seguridad nutricional de los productos alimentarios pertenecen a la esfera del soft law, a diferencia de las normas jurídicas del ámbito de la PAC y la inocuidad alimentaria.

h) Las competencias que ejerce la UE en materia de nutrición son de apoyo, coordinación y complemento a las acciones de los Estados miembros (EM), la Unión es plenamente competente para adoptar actos jurídicamente vinculantes en materia de salud alimentaria, y por tanto en también en lo que respecta a la seguridad nutricional.

\subsubsection{Evolución de las normas de la salud alimentaria}

Se observa que el desarrollo y evolución de las normas jurídicas en materia de salud alimentaria suelen tener relación con el grado de desarrollo económico de las sociedades en las que éstas rigen. Las sociedades pobres comienzan desarrollando en primer lugar reglamentaciones a través de las cuales se impulsan y ejecutan políticas alimentarias que tienen por objeto la explotación agropecuaria; como ocurrió en Europa después de la Segunda Guerra Mundial, con el desarrollo de la PAC en el seno de la Comunidad Económica Europea (CEE). A medida que estas sociedades alcanzan mayor desarrollo económico, la propia dinámica económica, caracterizada por la sofisticación e industrialización del comercio de los productos alimentarios, exige el desarrollo de nuevas normas jurídicas cuyo objeto es garantizar la inocuidad de esos productos. El colmo de la satisfacción de necesidades propias de la seguridad alimentaria, y la intensificación del comercio de productos alimentarios (debido al aumento del consumo, de la liberalización del comercio y de la eficiencia de la industria alimentaria), provocan procesos de transición nutricional negativa, ${ }^{59}$ en los que aumenta el riesgo de una ingesta crónica y excesiva de nutrientes o sustancias afines que supongan un efecto nocivo para la salud. Como consecuencia resulta necesario el desarrollo de normas que garanticen la seguridad nutricional de los productos alimentarios, al igual que hizo falta en su momento, desarrollar instrumentos jurídicos que garantizaran la inocuidad de éstos. Muchos países se

${ }^{59}$ Estos procesos se examinarán con mayor detenimiento en el capítulo 3.

Revista de Direito Brasileira | São Paulo, SP | v. 18 | n. 7 | p. 463 - 503 |Set./Dez. 2017 
encuentran afectados por estos procesos de transición nutricional negativa, lo que presagia la paulatina incorporación de normas jurídicas que garanticen la seguridad nutricional de los productos alimentarios, que se irán asimilando a toda política alimentaria voluntariosa, como decía CASTANG. ${ }^{60}$

\section{LA INDUSTRIA ALIMENTARIA Y EL DISEÑO DE LAS POLÍTICAS PÚBLICAS}

Una vez concretado el el alcance y contenido de lso términos de obesidad, alimento, seguridad e inocuidad alimentaria, nos preguntamos cual es papel de a industria alimentaria . Para ello resulta interesante revisar las similitudes que otras industrias como la del tabaco y del alcohol presentan para influir en las políticas de salud pública. ${ }^{61}$

En este sentido, las evidencias recogidas a través de la literatura analizada, señalan que la industria alimentaria utiliza todos los medios que tiene a su alcance con el objetivo de intervenir en las políticas alimentarias y de salud pública; dicha intervención persigue el fin último de influir en la regulación. Así pues, la intervención de la industria en las políticas públicas se realiza a través de diversas acciones, de entre las que destacan el lobby o cabildeo, el revolving door o puertas giratorias, y las alianzas con el sector público y/o privado.

\subsection{Los sistemas de regulación voluntaria}

En vista que los enfoques de intervención pública se han centrado fundamentalmente en la conducta de las personas como causa y a la vez solución de la ESO, regular las prácticas de la industria que contribuyen a la expansión de la epidemia han quedado relegadas a un segundo plano.

La mayoría de los gobiernos nacionales prefieren sistemas de regulación voluntaria para regular algunas de las actividades de la industria alimentaria, ${ }^{62}$ consideradas como factores que inciden en la ESO, como la composición nutricional de los productos ultra procesados, el marketing agresivo, el etiquetado nutricional, entre otros. Estos sistemas de regulación voluntaria implican la desregulación de los sistemas alimentarios, lo cual incide en la prevalencia de la ESO. Estudios independientes establecen una relación de causa y efecto entre la desregulación y el aumento de consumo de productos ultra procesados, lo que contribuye en definitiva a aumentar considerablemente la prevalencia de sobre peso y obesidad: "Fast food consumption is an independent predictor of mean BMI in high-income countries. Market deregulation policies may contribute to the obesity epidemic by facilitating the spread of fast food. "63

Se observa pues, que hay una desregulación que afecta no sólo a las cuestiones que tienen que ver directamente con la producción, comercialización y promoción de los productos alimentarios, o incluso con los procesos de integración económicas; sino que también le afecta a los sistemas alimentarios debido a la liberalización del comercio, como ha quedado demostrado en diversos estudios como el de THOW y HAWKES:

\footnotetext{
${ }^{60}$ Vid. CASTANG, Charles: Política y Derecho alimentario en la Comunidad Económica Europea. 1992. pág. 66. Disponible http://repositori.uji.es/xmlui/bitstream/handle/10234/104018/Castang_Pol\%EDtica_1992.pdf?sequence=1Accedido el 12 de enero de 2015

${ }^{61}$ Vid. BROWNELL, Kelly D.; WARNER, Kenneth E. "The perils of ignoring history: Big Tobacco played dirty and millions died. How similar is Big Food?". Milbank Quarterly, 2009, vol. 87, no 1, pág. 259-294.

${ }^{62}$ Vid. SWINBURN, Boyd, et al.:" Strengthening of accountability systems to create healthy food environments and reduce global obesity." The Lancet, 2015, vol. 385, no 9986, pág. 2536.

${ }^{63}$ Cfr. DE VOGLI, Roberto; KOUVONEN, Anne; GIMENO, David: "The influence of market deregulation on fast food consumption and body mass index: a cross-national time series analysis". Bulletin of the World Health Organization, 2014, vol. 92, no 2, pág. 99.
}

Revista de Direito Brasileira | São Paulo, SP | v. 18 | n. 7 | p. 463 - 503 | Set./Dez. 2017 
"This study indicates that the policies of trade liberalization in Central American countries over the past two decades, particularly in relation to the United States, have implications for health in the region. Specifically, they have been a factor in facilitating the "nutrition transition", which is associated with rising rates of obesity and chronic diseases such as cardiovascular disease and cancer. Given the significant cost of chronic disease for the health care system, individuals and the wider community, it is critical that preventive health measures address such upstream determinants of poor nutrition.". ${ }^{64}$

Existen datos suficientes que sostienen que la desregulación de la industria alimentaria y la liberación del comercio de los productos alimentarios, está relacionada con el aumento del consumo de productos ultra procesados y por ende con el aumento de la prevalencia de la ESO. De hecho en la práctica los sistemas de regulación voluntaria, ya sea la autorregulación o la corregulación, han fracasado estrepitosamente. ${ }^{65}$ Las causas son fundamentalmente que la industria no cumple con los objetivos propuestos, no se prevén sanciones disuasorias, ni se establece responsabilidades. ${ }^{66} 67$ Los sistemas de regulación voluntaria implican que la industria tenga que llevar a cabo iniciativas de que den prioridad a los intereses de salud pública por encima de los suyos, y que además se sometan a sanciones que ella misma debe juzgar y aplicar, lo que inevitablemente genera conflictos de interés. Precisamente uno de los principios del Derecho alimentario establece que los intereses económicos nunca pueden estar por encima de la dignidad de la persona ${ }^{68}$ y los intereses de la salud pública; ${ }^{69}$ por lo que partiendo de este principio, y previendo una probable colisión entre los intereses económicos de la industria y la salud pública, se aconseja la regulación obligatoria de los factores que comprometan la salud pública, en concreto los que incidan en la ESO.

Así pues, la principal barrera para que estos sistemas de regulación voluntaria funcionen, se encuentran en los conflictos de interés que inevitablemente se producen en el seno de la industria alimentaria, que hace simplemente inviable que la industria se regule a sí misma en lo concerniente a cuestiones críticas como el marketing, la publicidad, el etiquetado alimentario, la composición nutricional, entre otros. Se pueden citar algunos ejemplos que evidencian la falta de iniciativa por parte de la industria en cuestiones clave en lo no ha querido autorregularse. Destacan por ejemplo la no implementación de las recomendaciones firmes de la OMS en cuanto a la composición nutricional de los productos alimentarios, concretamente en lo que respecta la sodio, azúcar y ácidos grasos trans.

\subsection{El Derecho de la alimentación}

Si entendemos que la epidemia de sobrepeso y obesidad es de naturaleza alimentaria, resulta lógico pretender encontrar una disciplina jurídica cuyos fines, fundamentos y principios se

${ }^{64}$ Vid. THOW, Anne Marie; HAWKES, Corinna: “ The implications of trade liberalization for diet and health: a case study from Central America” Globalization and health, 2009, vol. 5, no 1, pág. 13.

${ }^{65}$ Vid. STUCKLER, David; NESTLE, Marion: “ Big food, food systems, and global health”. PLoS Med, 2012, vol. 9, no 6, pág. e1001242. (2)

${ }^{66}$ Vid. PANJWANI, Clare; CARAHER, Martin: "The Public Health Responsibility Deal: brokering a deal for public health, but on whose terms?”. Health Policy, 2014, vol. 114, no 2, pág. 171.

${ }^{67}$ Vid. SWINBURN, Boyd, et al.: "trengthening of accountability systems to create healthy food environments and reduce global obesity”. The Lancet, 2015, vol. 385, no 9986, pág. 2534-2545. (1)

${ }^{68}$ En este sentido la profesora MENDEZ ROCASOLANO plantea una nueva versión de la dignidad humana vinculada a los nuevos retos jurídicos de la actualidad, como el derecho alimentario representa. Se recomienda para mayor abundamiento la lectura de MENDEZ ROCASOLANO María: "Versión actual de dignidad de la persona: un nuevo paradigma para los derechos humanos en época de crisis" en Problemática de los derechos humanos fundamentales en américa latina y europa desafíos materiales y de eficacia, Marcial Pons, 2012 págs 111 a 120.

${ }^{69}$ En este sentido destaca el Tratado de Derecho alimentario de Angel RECUERDA. Op.Cit. 
encuentren en el ámbito de la alimentación, las herramientas e instrumentos jurídicos que hagan posible dar respuesta a los complejos problemas que se plantean a partir del hecho alimentario. Sin embargo, no está claro que exista tal disciplina jurídica, donde convergen dos nociones aparentemente simples, pero realmente complejas y ambiguas, como son el Derecho y la alimentación. $^{70}$

BIGWOOD y GÉRARD reconocían ya en 1970 la existencia de "un sector particular del Derecho, aplicable al conjunto de productos o sustancias que pueden servir para la alimentación del hombre o susceptibles de ser absorbidas por él." ${ }^{, 71}$ Es verdad que desde hace varias décadas surgen nuevas normas que tienen que ver con la alimentación, pero que no necesariamente cruzan la alimentación y el Derecho. Al contrario, del análisis de la legislación alimentaria en general y de la europea en particular, parece más bien que de hecho confluyen el Derecho y el comercio de productos alimentarios. El derecho parece preocuparse más por las cuestiones económicas y menos por las sociales que se derivan del hecho alimentario. En este sentido BIGWOOD y GÉRARD se refieren a los productos y sustancias que "pueden servir a la alimentación del hombre", definen correctamente la esencia de la realidad jurídica que supone la necesidad de la aparición de un Derecho de la alimentación que regule los sistemas alimentarios con el fin de que éste provea productos y sustancias que garanticen una dieta saludable; o sea, que garanticen la salud alimentaria. El Derecho de la alimentación se manifiesta como una nueva realidad jurídica aspira a regular el hecho alimentario como un hecho social, aunque en la actualidad las normas alimentarias tiendan a hacerlo del hecho económico. La alimentación de las personas requiere ser protegida en función a consideraciones sociales antes que económicas; en otras palabras, debe ser protegida de las pretensiones económicas de explotación de las necesidades alimentarias, sobre todo de los sectores de la población más vulnerables.

En oposición, HERRERA crítica las tendencias sociales de la concepción del Derecho de la alimentación que defienden BIGWOOD y GÉRARD; "E. J. BIGWOOD y A. GÉRARD, en su obra Objetivos y principios fundamentales de un derecho comparado (1970), no hablan de Derecho alimentario sino de Derecho de la alimentación. El concepto de dichos autores es de ámbito más general, incluso se puede decir que se refieren a un Derecho alimentario con carácter más social y menos científico." ${ }^{2}$ No podemos estar más en desacuerdo con HERRERA; el hecho alimentario es ante todo un hecho social antes que científico y económico. Las normas y principios jurídicos que pretendan regular el hecho alimentario desde una concepción que no sea la social, no regula un hecho alimentario; regula quizás un hecho económico, o científico según HERRERA.

Nos encontramos pues, que para regular los factores que inciden en la grave crisis alimentaria de malnutrición que es la ESO, se requiere de una rama del Derecho que se encuentra aún por cristalizar. El estudio de la disciplina jurídica a la que nos referimos es en gran medida compleja, por el escaso desarrollo doctrinal con que cuenta, que dificulta no sólo la aparición de una teoría general de un Derecho de la alimentación, más allá del simple comentario o análisis de la legislación alimentaria que presumiblemente, la mayoría de los estudiosos del Derecho alimentario actuales aspiran.

Preocupa ubicar el estudio del problema planteado dentro de la disciplina jurídica más afín a la naturaleza del problema. Al ir al encuentro de esta disciplina topamos nos hemos encontrado serios problemas al identificar (incluso) su denominación, su naturaleza jurídica, su objeto, sus principios y fundamentos

La denominación de esta incipiente rama del Derecho no es del todo pacífica; si bien es cierto que se suele usar con mayor frecuencia el término Derecho alimentario. BIDWOOD y

\footnotetext{
${ }^{70}$ Ibídem.

${ }^{71}$ Cfr. BIGWOOD y GÉRARD, Op. Cit., pág. 3.

72 Cfr. HERRERA, Rosa María Blanca.: La bipolaridad del Derecho alimentario. En UE, Sociología y Derecho alimentarios: estudios jurídicos en honor de Luis González Vaqué. Editorial Aranzadi, 2013, pág. 99.
}

Revista de Direito Brasileira | São Paulo, SP | v. 18 | n. 7 | p. 463 - 503 | Set./Dez. 2017 
GÉRARD prefieren utilizar el término Derecho de la alimentación, según éstos para evitar confusiones con las obligaciones alimentarias entre parientes. ${ }^{73}$ El término Derecho de la alimentación, parece el más apropiado porque evoca su naturaleza social, y ayuda construir un muro dialéctico delimitador frente a aspiraciones de naturaleza más bien economicista.

Se encuentran en la doctrina varias definiciones de Derecho de la alimentación o alimentario. RECUERDA GIRELA define al Derecho alimentario como "una rama de la ciencia del Derecho que tiene por objeto el estudio de las normas jurídicas y principios cuya finalidad sea garantizar la seguridad alimentaria y la calidad de los alimentos."74 Esta definición resulta bastante imprecisa porque no está claro qué entiende el autor por seguridad alimentaria y por calidad alimentaria (se intuye que se refiere a la inocuidad de los alimentos y a los atributos específicos de los productos alimentarios que el consumidor considere apetecibles, respectivamente); y limitada, porque no abarca toda la realidad del hecho social alimentario, que incluye la seguridad alimentaria y la seguridad nutricional.

HERRERA define el Derecho alimentario como "la ciencia que regula los aspectos jurídicos de los alimentos. ${ }^{, 75}$ Esta definición es ciertamente simple, aunque dispersa y poco clara. Parece anteponer el aspecto jurídico de los alimentos, a los hechos que requieren regulación, a través de los cuales adquieren éstos (los alimentos) tal relevancia jurídica. Es decir; según esta definición los aspectos no jurídicos de los alimentos quedan fuera del alcance del Derecho alimentario, aunque obviamente adquirirán tal carácter jurídico cuando el Derecho se preocupe por ellos; o sea, según HERRERA se intuye que el Derecho alimentario es la ciencia que regula los alimentos, lo cual termina siendo una definición demasiado amplia.

BARROS define al Derecho alimentario como:

"el conjunto de principios, disposiciones, métodos y actuaciones que regulan, bajo criterios jurídicos, los aspectos genéricos y específicos de los alimentos, bebidas y productos alimentarios, en las áreas de la producción, manipulación, elaboración, conservación, transporte, comercialización, etiquetado, publicidad, normalización, inspección, vigilancia y represión, en su caso; todos ellos con dos objetivos prioritarios: la protección del consumidor y el mantenimiento de la honradez en las transacciones comerciales." ${ }^{, 76}$

Esta definición acierta a considerar como objetivos del Derecho alimentario la protección del consumidor, aunque es criticable el hecho que se centre en los alimentos como un producto. Esto implica una concepción economicista del Derecho alimentario, que consideramos no pertenece al ámbito natural del mismo, reforzándose la inclusión de la honradez de las transacciones comerciales, que como tales pertenecen a otra rama del Derecho.

Continuando con BIGWOOD y GÉRARD entienden un Derecho de la alimentación como "los sistemas de reglas jurídicas que organizan y limitan las actividades de producción, de acondicionamiento y de comercio de los productos alimenticios, tomando como base ciertos principios, cuyas modalidades varían considerablemente con los productos considerados."77 Definición que puede encontrar una importante limitación en el sentido que su alcance sólo abarca los productos alimenticios. Tampoco convence la subjetividad que implica supeditar dicho sistema de reglas jurídicas a ciertos principios indeterminados.

\footnotetext{
${ }^{73}$ Vid. BIGWOOD y GÉRARD, Op. Cit., pág. 4.

${ }^{74}$ Cfr. RECUERDA GIRELA, Miguel Ángel: Tratado de Derecho Alimentario. Aranzadi,Pamplona 2011 , pág. 87.

${ }^{75}$ Cfr.. HERRERA, Rosa María Blanca.: La bipolaridad del Derecho alimentario. En UE, Sociología y Derecho alimentarios: estudios jurídicos en honor de Luis González Vaqué. Editorial Aranzadi, 2013, pág.101.

${ }^{76}$ Citado por HERRERA, Rosa María Blanca, en La bipolaridad del Derecho alimentario. En UE, Sociología y Derecho alimentarios: estudios jurídicos en honor de Luis González Vaqué. Editorial Aranzadi, 2013, pág.101.

${ }^{77}$ Cfr. BIGWOOD y GÉRARD, Op. Cit, pág. 16.
} 
En general, resulta deficitario la mayoría de las definiciones de Derecho de la alimentación o alimentario, al excluir todas ellas la noción de alimentación, al mismo tiempo que parece ineludible atribuir al Derecho de la alimentación funciones de protección al comercio de productos alimentarios. Se presenta el Derecho de la alimentación como el conjunto de normas y principios jurídicos cuyo objeto es garantizar la salud alimentaria, lo cual se consigue a través de la seguridad alimentaria, la inocuidad de los productos alimentarios y la seguridad nutricional.

De esta definición se desprende que el objeto del Derecho de la alimentación es garantizar la salud alimentaria, excluyendo toda aspiración por la protección de las transacciones comerciales alimentarias, los aspectos relacionados con el fraude o falsificación de productos alimentarios, entre otros, pues pertenecen a otro ámbito del Derecho. La norma alimentaria pura se debe a la protección de la salud alimentaria. La preocupación por la delimitación aséptica de la norma alimentaria radica en facilitar la determinación de su naturaleza jurídica; bastante incierta hasta ahora, tanto que se cuestiona si las legislaciones alimentarias pueden ser consideradas o no como un verdadero Derecho de la alimentación ${ }^{78}$

Hay una una pluralidad de normas de diversa naturaleza jurídica integradas en la legislación alimentaria, que dificulta la determinación de la naturaleza jurídica del Derecho de la alimentación. Por su parte el Derecho alimentario se encuentra bien delimitado dentro de las normas que tienen por objeto garantizar la salud alimentaria, por lo que consideramos que su naturaleza jurídica pertenece al ámbito del Derecho social, entendido éste como:

"conjunto de leyes y disposiciones autónomas que establecen y desarrollan diferentes principios y procedimientos protectores a favor de las personas, grupos y sectores de la sociedad integrados por individuos económicamente débiles, para lograr su convivencia con las otras clases sociales dentro de un orden justo., 79

Existe cierto consenso en reconocer que los objetivos o fines del Derecho de la alimentación se resumen en dos; a saber, la salud del consumidor y la honradez de las transacciones comerciales. Se tiene referencia de estos fines, al menos desde la presentación de FRENZEL de un informe titulado "Los principios básicos de las legislaciones de la alimentación, divergencias y dificultades para una armonización," para el coloquio internacional de 1964 en el instituto de estudios europeos de la universidad de Bruselas. ${ }^{80}$ Otros autores como HERRERA ${ }^{81}$, BIGWOOD y GÉRARD, o VILLAR PALASÍ, ${ }^{82}$ se han manifestado a favor de reconocer tales

\footnotetext{
${ }^{78}$ En este sentido “..., se puede estimar que el conjunto de reglas-imperativas o restrictivas- que afectan a una categoría determinada de la actividad humana, constituye el "derecho" propio de esta actividad. Estas reglas, aplicadas a la fabricación y al comercio de los productos alimenticios, son consideradas generalmente como reglas que deben asegurar la policía del comercio. Están integradas - a este título o a otro cualquiera- en el código comercial o el código penal (falsificación, fraude) de los Estados, según la naturaleza de las disposiciones. En la medida en que se relacionan más directamente con la protección de la salud, lo mismo se las podría considerar con preferencia como reglamentaciones de carácter social. Según otro criterio, no es menos cierto que toda reglamentación que afecta a la producción y a la venta de productos de consumo, y, entre éstos, a las de los productos alimenticios, tiene consecuencias directas sobre la vida económica y puede serconsiderada, por consiguiente, en el sentido amplio de la palabra, como perteneciente al Derecho económico. En fin, si nos referimos a la naturaleza imperativa o represiva de las reglas, nos veremos inclinados a considerarlas como reglamentaciones de derecho administrativo, dependientes de la autoridad pública, para garantizar el respeto del interés público". Vid. BIGWOOD y GÉRARD, Op. Cit., pág. 5

${ }^{79}$ Citado por TINOCO, C.; LUGO, S.: "El trabajo no es artículo de comercio". Revista Latinoamericana de Derecho Social, 2013, vol. 17, p. 68.

${ }^{80}$ Vid. BIGWOOD y GÉRARD, Op. Cit., pág. 3

${ }^{81}$ Vid. HERRERA, Rosa María Blanca.: La bipolaridad del Derecho alimentario. En UE, Sociología y Derecho alimentarios: estudios jurídicos en honor de Luis González Vaqué. Editorial Aranzadi, 2013, pág.101.

${ }^{82}$ Citado por RECUERDA GIRELA, Miguel Ángel en Tratado de Derecho Alimentario. Aranzadi,Pamplona 2011, pág. 118.
}

Revista de Direito Brasileira | São Paulo, SP | v. 18 | n. 7 | p. 463 - 503 | Set./Dez. 2017 
cuestiones como fines del Derecho de la alimentación, aunque ampliándolos. BIGWOOD y GERÁRD plantean como fines del Derecho de la alimentación, la honradez en las transacciones comerciales, la protección de la salud, la regularización de la vida económica, la protección del trabajo y la información al consumidor. ${ }^{83}$ HERRERA por su parte, señala que los elementos que guían y orientan el Derecho alimentario son evitar el fraude alimentario, la protección de la salud, la regulación de la economía, y la información del consumidor. ${ }^{84}$

Un aspecto importante a considerar en el ámbito del Derecho de la alimentación son los principios jurídicos que le rigen y fundamentan. No es tarea fácil determinar los principios los principios jurídicos en general. En el caso del Derecho de la alimentación, a pesar de existir ciertos valores morales universales que inspiran la norma alimentaria. En este sentido, tampoco creemos que los principios de la legislación alimentaria de la Unión, establecidos por el legislador europeo en el Reglamento 178/2002, y de los que le dedicamos un apartado en el capítulo IV de este trabajo, puedan considerarse exclusivamente como los principios jurídicos del Derecho de la alimentación.

\begin{abstract}
"Nadie, ni siquiera los formalistas más duros y puros, estaría dispuesto a afirmar que sólo deben ser considerados principios aquellos que así son llamados por el legislador. Generalmente se opina que, por un lado, unos supuestos «principios», así llamados por el legislador, no son efectivamente tales, y, por el otro y sobre todo, que muchos enunciados jurídicos son (o expresan) principios, aun si el legislador no lo dice explícitamente. En otras palabras, el nomen iuris de «principio» no es condición ni necesaria ni suficiente para identificar un principio jurídico." ${ }^{85}$
\end{abstract}

Tampoco los pocos esfuerzos doctrinales convencen a la hora delimitar con claridad los principios del Derecho de la alimentación. Destaca la labor de RECUERDA GIRELA, que se atreve a enumerar dichos principios en cientificidad, prioridad de la salud sobre los intereses económicos, globalidad, horizontalidad, integridad, principio de transparencia, principios de proporcionalidad y no discriminación, principio de prevención, y principio de precaución o cautela. ${ }^{86}$ No queda claro si RECUERDA GIRELA se refiere a los principios de un Derecho alimentario universal, o de los principios de un Derecho alimentario europeo, puesto que el mismo autor ha publicado sendas obras haciendo referencia a estos principios para uno u otro ámbito. De todos modos, en uno u otro caso, la concepción tan limitada de Derecho alimentario de este autor (sólo considera la garantía de la inocuidad de los productos alimentarios y la calidad alimentaria como el objeto del Derecho alimentario). Asimismo otros autos como VAN DER MEULEN, también se refiere a los principios del Derecho alimentario europeo, pero en base a los que se encuentran en el Reglamento $178 / 2002 .^{87}$

Surge la pregunta sobre la existencia de un sistema de normas jurídicas autónomo, articulado en torno a cierto principios jurídicos y valores morales dentro del ámbito de la alimentación más allá del comercio de productos alimentos. A lo sumo en la Unión Europea existe, si cabe, una legislación alimentaria. Todavía casi 50 años después, el diagnóstico de BIGWOOD Y GÉRARD sobre la existencia de un Derecho de alimentación aún en desarrollo está vigente que:

\footnotetext{
${ }^{83}$ Vid. BIGWOOD y GÉRARD, Op. Cit., pág 28.

${ }^{84}$ Vid. HERRERA, Op. Cit., pág 101.

85 Cfr. Comanducci, Paolo. "Principios jurídicos e indeterminación del derecho." (1998). Disponible en https://rua.ua.es/dspace/bitstream/10045/10350/1/doxa21-2_07.pdf. Accedido el 01 de febrero de 2017.

${ }^{86}$ Vid. Girela, Miguel Ángel Recuerda. "Los principios generales del derecho alimentario europeo= General principles of european food right." Revista de Derecho de la Unión Europea 26 (2014): 171.

${ }^{87}$ Vid. VAN DER MEULEN, Bernd MJ. "The structure of European food law.” Laws, 2013, vol. 2, no 2, p. 69-98.
}

Revista de Direito Brasileira | São Paulo, SP | v. 18 | n. 7 | p. 463 - 503 |Set./Dez. 2017 


\begin{abstract}
"Es incontestable que el desarrollo actual de las legislaciones en este dominio, su creciente complejidad y, sobre todo, su tendencia a articularse alrededor de ciertos principios directores, expresados por leyes concretas o por textos de alcance general, dan lugar a reglamentaciones de las sustancias alimenticias que no son otra cosa que un conjunto de disposiciones incoherentes que se integran, más o menos armoniosamente, en el aparato legislativo económico o represivo de un país. Pero si estas legislaciones tienden a construir, en la mayoría de los Estados, un derecho de la alimentación autónomo, sus vacilaciones y su falta de homogeneidad demuestran que se encuentran todavía, en la actualidad, en un período de transición, caracterizado por la confrontación de intereses económicos y sociales (productores, distribuidores y consumidores), los cuales pueden ser, según los casos, convergentes, solidarios o contradictorios." ${ }^{88}$
\end{abstract}

El estado ominoso de los sistemas alimentarios actuales, cuya manifestación más visible y aberrante es la ESO, son muestra que el Derecho de la alimentación se encuentra todavía en un período de transición, en donde se encuentran enfrentados intereses económicos y sociales.

\title{
3. LOS PRODUCTOS ULTRA PROCESADOS , LA ESO Y EL DERECHO
}

Dentro de los factores involucrados en la ESO, los productos ultra procesados son considerados la Escila y el Caribdis de esta epidemia que se cierne hoy sobre la humanidad.

Si bien es cierto que la propiedad de nutrir del alimento adquiere una certeza dogmática entre todas las disciplinas científicas ${ }^{89}$ los productos ultra procesados se caracterizan, entre otras cosas, por ser nutricionalmente pobres, llegando en algunos casos a no aportar ningún valor nutricional. Así pues, siendo que la propiedad nutritiva es la principal característica de los alimentos, y que los productos ultra procesados son nutricionalmente deficientes, resulta pertinente estudiar qué lugar ocupan éstos dentro de la clasificación de los alimentos, si es que desde un punto de vista científico pueden considerarse como tal.

En este sentido, no resulta sencillo hacer una clasificación general de los alimentos, puesto que ésta depende de los criterios que se tomen en cuenta para tal fin. Sin embargo, no por ello se renuncia a analizar el lugar que ocupan los productos ultra procesados según sean los criterios de clasificación de los alimentos, puesto que dicho análisis puede arrojar indicios muy valiosos a la hora de determinar la naturaleza, características y efectos de éstos en la salud de las personas y más concretamente, las relacionadas con la prevalencia de la ESO.

Así pues, se ha considerado los siguientes criterios de clasificación de los alimentos para intentar determinar qué lugar ocupan los productos ultra procesados dentro de éstos:

a) los que tienen que ver con las directrices dietéticas;

b) según la función que realicen; y

c) según los criterios basados en el grado de transformación de los alimentos.

\subsection{Criterios para la clasificación de los alimentos}

a) Las directrices dietéticas

Las clasificaciones que se hacen a partir de las directrices dietéticas basadas en alimentos, varían según sea la población a la que se dirigen, con el fin de promocionar el bienestar nutricional. ${ }^{90}$ Es por ello que su redacción se suele presentar de forma simple a través

\footnotetext{
${ }^{88}$ Cfr. BIGWOOD y GÉRARD, Op. Cit., pág. 15

${ }^{89}$ Recuérdese que esta certeza dogmática coincide con la concepción vulgar que en general se tiene de los alimentos.

${ }^{90}$ Vid. MARTÍNEZ, J. Alfredo; ANCHÍA, Iciar Astiasarán; FRITSCH, Herlinda Madrigal (ed.).: Alimentación y salud pública. Madrid: McGraw-Hill Interamericana, 2002. pág. 81
}

Revista de Direito Brasileira | São Paulo, SP | v. 18 | n. 7 | p. 463 - 503 | Set./Dez. 2017 
de mensajes claros, comprensibles y atractivos, que anime a las personas a consumir los alimentos que se promocionan en dichas recomendaciones y objetivos nutricionales. ${ }^{91}$ En otras palabras, la clasificación que se hace de los alimentos no obedece a criterios científicos según su naturaleza o composición nutricional, sino más bien a criterios que van en función de las recomendaciones que los gobiernos tengan a bien promocionar atendiendo principalmente a razones de salud y bienestar nutricional, pero considerando también otros criterios, como pueden ser razones de carácter cultural. No obstante, esta clasificación, si se quiere arbitraria, ayuda a las personas a elegir los alimentos que comen, la frecuencia con que los comen y la cantidad en que los comen.

Así pues, dichas directrices suelen clasificar los alimentos por grupos, los cuales pueden variar según el país que las elabore. Para facilitar la compresión de los mensajes que se quieren transmitir a través de las guías o directrices alimentarias, se suelen elaborar instrumentos didácticos visuales como pirámides, ruedas, platos, o escaleras, entre otros, en los que se presentan una serie de grupos de alimentos que al incluirse en la dieta de las personas en la forma recomendada, repercute positivamente en la salud, existiendo marcadas diferencias en cuanto a los grupos de alimentos según la guía y/o país que se consulte.

En España la pirámide alimentación saludable elaborada en 2015 por la Sociedad Española de Nutrición Comunitaria (SENC) clasifica a los alimentos en cinco grupos: 1) hidratos de carbono y granos enteros; 2) frutas, verduras y hortalizas; 3) proteínas y lácteos; 4) carnes rojas, procesadas y embutidos; 5) alimentos ultra procesados, azúcares, grasas y sal. ${ }^{92}$ Si bien es cierto que el efecto de visualizar una pirámide alimentaria o cualquier instrumento didáctico equivalente es más eficaz que la simple descripción de los grupos de sus alimentos, la pirámide española elaborada en 2015 por la SENC no ofrece con claridad qué alimentos en concreto pertenecen a cada grupo. En España la Agencia Española de Consumo, Seguridad Alimentaria y Nutrición ofrece una alternativa a la pirámide alimentaria de la SENC, a través de la Estrategia para la Nutrición, Actividad Física y Prevención de la Obesidad (Estrategia NAOS) que ha elaborado la pirámide NAOS; sin embargo, es aún más ambigua e incluye también a los productos ultra procesados dentro de una serie de alimentos que se muestran en dicha pirámide. No obstante, existe en España un referente en cuanto a guías alimentarias, llamada la Rueda de los Alimentos que data de la década de los $80,{ }^{93}$ elaborada por VIVANCOS, PALACIOS y GARCÍA ALMANSA y divulgada por el programa de Educación en Alimentación y Nutrición (EDALNU). En dicha rueda se clasifican los alimentos en siete grupos: 1) Leche y derivados (excepto mantequilla); 2) Carne, pescado y huevos; 3) Patatas, legumbres y frutos secos; 4) Verduras y hortalizas; 5) Frutas; 6) Cereales, azúcar, miel; 7) Aceite, mantequilla, margarina y tocino. $^{94}$

El caso del Reino Unido es muy interesante. En todo el Reino Unido los indicadores de salud relacionados con la ESO son alarmantes, por ejemplo en un trabajo de 2001 se estimó que sólo en Inglaterra mueren de forma prematura a causa de la obesidad más 30000 personas al año. ${ }^{95}$ Por ello, la ESO ha sido objeto de preocupación e intenso debate público, por lo que se ha dedicado mucho esfuerzo en la investigación y en el diseño de políticas públicas anti obesidad, siendo uno de los países donde más se están preocupando por aplicar medidas que conlleven a frenar el avance de la epidemia. The Eatwell Guide o la guía del buen comer, es un ejemplo de

\footnotetext{
${ }^{91}$ Ibídem.
}

92 Vid. http://www.nutricioncomunitaria.org/es/noticia/piramide-de-la-alimentacion-saludable-senc-2015. Consultada el 25 de mayo de 2016.

${ }^{93}$ Vid. CANDELAS, R.; ALTARRIBA, M. L.; LÓPEZ, A.: Nutrición en el climaterio. Informe de S VMFYC, Valencia, España. pág. 13.

${ }^{94}$ Cfr. ROJAS, Rafael Moreno: Nutrición y dietética para tecnólogos de los alimentos. Ediciones Díaz de Santos, 2013. pág. 202.

${ }^{95}$ Vid. BOURN, J. Tackling obesity in England. The Stationery Office, London, UK, 2001. Pág. 16 Revista de Direito Brasileira | São Paulo, SP | v. 18 | n. 7 | p. 463 - 503 |Set./Dez. 2017 
éstas. En esta guía se divide los alimentos en cinco grupos: 1) frutas y vegetales; 2) frijoles, legumbres, pescado, huevos, carne y otras proteínas; 3) productos lácteos y derivados; 4) aceites; y 5) patatas, pan, arroz, pasta y otros carbohidratos con almidón. ${ }^{96}$ La Guía del Buen Comer británica se publicó por primera vez en marzo de 2016 en sustitución a The Eatwell Plate. Uno de los principales cambios con la nueva guía se produjo en torno a los productos ultra procesados, que quedaron fuera de la imagen principal donde se recogen los cinco grupos en los que la guía clasifica los alimentos, pero haciendo mención a éstos con imágenes al margen, recomendando consumirlos en pocas cantidades y con poca frecuencia. ${ }^{97}$

En todo el mundo existen muchos ejemplos similares al de España o el Reino Unido. A continuación, se analizará la clasificación que hacen por grupos las guías alimentarias de dos países por continente. Por Europa se ha revisado las guías alimentarias de Alemania y Portugal; por América, Estados Unidos y México; por Asia, Japón y China; por África, Namibia y Sudáfrica; y por Oceanía sólo se encontraron datos de Australia.

Alemania ha elaborado el círculo de nutrición como su guía alimentaria en donde se divide los alimentos en siete grupos: 1) cereales y patatas; 2) vegetales; 3) frutas; 4) leche y productos lácteos; 5) carnes, salchichas, pescado y huevos; 6) grasas y aceites; y 7) bebidas. ${ }^{98} 99$ La guía alimentaria de Portugal es una rueda de alimentos divididos en segmentos que representan a siete grupos de alimentos: 1) grasas y aceites; 2) leche y productos lácteos; 3) carne, pescado, mariscos y huevos; 4) legumbres; 5) patatas, cereales y sus productos; 6) hortalizas; y 7) frutas ${ }^{100}$.

En la guía alimentaria de Estados Unidos My Plate, se clasifican los alimentos en cinco grupos: 1) frutas; 2) verduras; 3) granos; 4) alimentos ricos en proteínas; 5) y grupos lácteos. En el caso de México, su guía alimentaria clasifica a los alimentos en tres grupos: 1) verduras y frutas; 2) cereales; y 3) leguminosas y alimentos de origen animal. ${ }^{101}$

En Japón la guía alimentaria está representada con una peonza y los alimentos se clasifican en cinco grupos: 1) cereales; 2) vegetales; 3) pescado, huevos y carne; 4) leche; y 5) fruta $^{102}$. En China su guía alimentaria está representada por una pagoda, y se clasifican los alimentos en cinco grupos: 1) cereales y tubérculos; 2) verduras y frutas; 3) carnes, aves, pescado y camarones, y huevos; 4) leche, productos lácteos, frijoles y productos de soja; 5) grasa, aceite y sal. ${ }^{103}$

En cuanto a Namibia, la guía de alimentación utilizada muestra cuatro grupos de alimentos: 1) cereales; 2) verduras y frutas; 3) alimentos de origen animal; y 4) frijoles, grasas, aceites y azúcar $^{104}$. La guía alimentaria de Sudáfrica clasifica a los alimentos en siete grupos: 1)

\footnotetext{
${ }^{96}$ Disponible en https://www.gov.uk/government/publications/the-eatwell-guide. Accedido el 25 de mayo de 2016.

97 The Eatwell Guide How does it differ to the eatwell plate and why?. Disponible en https://www.gov.uk/government/uploads/system/uploads/attachment_data/file/508183/Eatwell_guide_whats_change d_and_why_2016.pdf. Accedido el 25 de mayo de 2016.

98_ Disponible en http://www.fao.org/nutrition/education/food-based-dietary guidelines/regions/countries/germany/es/. Accedido el 26 de mayo de 2016.

${ }_{99}$ Disponible en https://www.dge.de/ernaehrungspraxis/vollwertige-ernaehrun/ernaehrungskreis/. Consultada el 26 de mayo de 2016. Accedido el 26 de mayo de 2016.

100 Disponible en http://www.fao.org/nutrition/education/food-based-dietary-guidelines/regions/countries/unitedstates/es/. Accedido el 26 de mayo de 2016.

${ }^{101}$ Disponible en http://www.fao.org/nutrition/education/food-based-dietary-guidelines/regions/countries/mexico/es/. Accedido el 26 de mayo de 2016.

102 Disponible en http://www.fao.org/nutrition/education/food-dietary-guidelines/regions/countries/japan/en/. Accedido el 26 de mayo de 2016.

103 Disponible en http://www.fao.org/nutrition/education/food-dietary guidelines/regions/countries/china/en/. Accedido el 26 de mayo de 2016

104 Disponible en http://www.fao.org/nutrition/education/food-dietary-guidelines/regions/countries/namibia/en/ Accedido el 26 de mayo de 2016
}

Revista de Direito Brasileira | São Paulo, SP | v. 18 | n. 7 | p. 463 - 503 | Set./Dez. 2017 
alimentos ricos en almidón; 2) verduras y frutas; 3) frijoles, guisantes, lentejas y soja; 4) pollo, pescado, carne y huevos; 5) leche, amasi y yogur ; 6) grasa y aceite; y 7) agua. ${ }^{105}$

La guía alimentaria australiana muestra los siguientes grupos de alimentos: 1) cereales; 2) verduras, legumbres y frijoles; 3) frutas; 4) carnes magras y aves de corral, pescado, huevos, queso de soja, nueces y semillas; 5) leche y productos derivados. ${ }^{106}$ De forma similar a la del Reino Unido, muestra una imagen de productos ultra procesados al margen de la imagen de los cinco grupos de alimentos, recomendando su consumo moderado y esporádico.

Como puede observarse, aunque existe una gran heterogeneidad en los grupos en los que las guías alimentarias clasifican a los alimentos, en la gran mayoría de los casos los productos ultra procesados quedan fuera de estos grupos. Este hecho en realidad no tiene una trascendencia jurídica ni científica, más allá de la estrecha relación que existe entre el consumo de éstos con sus propiedades nutricionales. En este sentido, puede parecer justificado no presentar los productos ultra procesados dentro de instrumentos visuales de los que se sirven las distintas guías alimentarias. Sin embargo, la estrategia utilizada por el Reino Unido y Australia es más realista y a la larga puede ser más eficaz, al excluir a los productos ultra procesados de los grupos de alimentos, pero mostrando una imagen de ellos al margen con las recomendaciones pertinentes. No mostrarlos pueden ocasionar confusión, puesto que las personas pueden interpretar erróneamente que algunos de sus ingredientes se encuentran dentro de algunos de los grupos de alimentos recomendados. Mostrarlos junto con el resto de grupos de alimentos, como es el caso de España, tampoco parece muy acertado, puesto que aunque se hagan las recomendaciones de consumo, se equiparan alimentos con propiedades nutritivas y energéticamente equilibrados con productos energéticamente densos y nutricionalmente pobres. La forma en que el organismo se enfrenta al deseo de consumo de unos y otros es muy diferente, y en el caso de los segundos pueden ser muy difícil de controlar por las características adictivas que poseen muchos de ellos. $^{107}$

b) Clasificación de los alimentos según la función que realicen:

Los alimentos contienen en su composición sustancias que según la labor que realicen, ${ }^{108}$ pueden clasificarse en alimentos plásticos, energéticos y reguladores. Estas sustancias son los nutrientes, por lo que alimentos ricos en determinados nutrientes que se encuentren incluidos en los tres grupos antes mencionados, se les llamas alimentos protectores, ${ }^{109}$ puesto que suplen la deficiencia de nutrientes que pudieran tener otros alimentos. ${ }^{110}$ Los criterios de clasificación de estos grupos de alimentos se hace en función a la proporción de nutrientes que se encuentran en los alimentos y no en el nutriente o sustancia propiamente dicho.

Así pues, la principal función de los alimentos plásticos es proporcionar proteínas, hierro y calcio, encontrándose entre estos alimentos la leche y los lácteos en general; carnes, pescados,

${ }^{105}$ Disponible en http://www.fao.org/nutrition/education/food-dietary-guidelines/regions/countries/south-africa/en/ Accedido el 26 de mayo de 2016

106 Disponible en http://www.fao.org/nutrition/education/food-dietary-guidelines/regions/countries/australia/en/ Accedido el 26 de mayo de 2016

107 Se analizará en profundidad sobre las características de los productos ultra procesados, en concreto sus propiedades adictivas, en un apartado ulterior, en este mismo capítulo.

${ }_{108}$ Vid. CANDELAS, R.; ALTARRIBA, M. L.; LÓPEZ, A.: Nutrición en el climaterio. Informe de SVMFYC, Valencia, España, pág. 10.

109 Vid. ROJAS MORENO Rafael.: Nutrición y dietética para tecnólogos de los alimentos. Ediciones Díaz de Santos, 2013, pág. 199.

${ }^{110}$ Se ha mencionado en apartados anteriores que los productos ultra procesados se caracterizan entre otras cosas por ser nutricionalmente pobres. El papel que desempeñan los alimentos protectores al suplir posibles deficiencias nutricionales en alimentos como la sandia o el pepino, no puede aplicarse a los productos ultra procesados, puestos que éstos son productos alimentarios desequilibrados que además de ser nutricionalmente pobres son energéticamente densos. No ocurre lo mismo con los ejemplos de alimentos antes citados, la sandia y el pepino.

Revista de Direito Brasileira | São Paulo, SP | v. 18 | n. 7 | p. 463 - 503 |Set./Dez. 2017 
huevos y vísceras; legumbres frutos secos y cereales. ${ }^{111}$ Son los que tienen la tarea de la formación, reparación y crecimiento de los tejidos.

Por su parte los alimentos energéticos como su nombre lo indica, suministran energía, como las grasas, mantecas y aceites; frutos secos y cereales; azúcar y miel. ${ }^{112}$

Por último, los alimentos reguladores se caracterizan por poseer elevadas cantidades de vitaminas y/o minerales, como las verduras y frutas frescas, hígado, huevos y lácteos; cereales integrales y legumbres. ${ }^{113} \mathrm{Su}$ función es fundamentalmente la formación, reparación y crecimiento de los tejidos. ${ }^{114}$

De lo dicho anteriormente se extrae que existen alimentos como los frutos secos y los cereales que por su composición nutricional se incluyen dentro de más de una categoría. A priori, los productos ultra procesados parecieran encajar en el grupo de los alimentos energéticos, debido a que son energéticamente densos. No obstante, el hecho que sea energéticamente densos, no necesariamente implica que pudieran incluirse dentro de este grupo. Los alimentos energéticos presentan ciertas características que no comparte con los productos ultra procesados; como atributos que tienen que ver con la saciedad; no se suelen consumir solos, sino que necesariamente están contenidos en otros alimentos que aportan otros nutrientes; pueden aportar un tipo de grasa beneficiosa para la salud como las poliinsaturadas, entre otros. Los productos ultra procesados son sustancias energéticamente densas que suelen atrofiar la percepción de la saciedad, se pueden consumir por sí solos y en grandes cantidades, suelen estar compuestos por grasas saturadas o calorías simples.

De esta manera, al analizar la composición nutricional de los productos ultra procesados, se deduce que no tienen cabida dentro de ningún grupo de alimentos que componen esta clasificación, ${ }^{115}$ puesto que son productos alimentarios nutricionalmente pobres y energéticamente densos. Si bien es cierto que los ultra procesados son en general hipercalóricos; es decir, pueden considerarse alimentos energéticos, su naturaleza y características, hace que no se les pueda tomar en cuenta dentro de esta clasificación.

c) Criterios en cuanto al grado de transformación de los alimentos:

Desde una visión bromatológica esencialmente industrial y en función al grado de transformación, los alimentos pueden clasificarse in lato sensu en alimentos sin trasformar o no elaborados y en alimentos transformados o procesados.

No obstante, existen grados de transformación o procesamiento. La Agencia Internacional para la Investigación sobre el Cáncer (IARC), utilizando una metodología diseñada por la European Prospective Investigation into Cancer and Nutrition (EPIC) clasifica a los alimentos, basado en el grado de su procesamiento en tres grupos principales: 1) los alimentos no

\footnotetext{
${ }^{111}$ Vid. ROJAS, Rafael Moreno. Nutrición y dietética para tecnólogos de los alimentos. Ediciones Díaz de Santos, 2013, pág. 199.

${ }^{112}$ Ibídem.

${ }^{113}$ ROJAS, MORENO, Rafael: Op.Cit. Pág. 199

${ }^{114}$ CANDELAS, R.; ALTARRIBA, M. L.; LÓPEZ, A.: Op.Cit. Pág 11.

115 Recuérdese que el propósito de este apartado es intentar encontrar el lugar de ocupan los productos ultra procesados dentro de una supuesta clasificación de los alimentos.
}

Revista de Direito Brasileira | São Paulo, SP | v. 18 | n. 7 | p. 463 - 503 | Set./Dez. 2017 
elaborados, 2) alimentos procesados moderadamente, y 3) alimentos altamente procesados. ${ }^{116} 117$ 118

Los alimentos no elaborados son aquellos consumidos crudos sin ningún procesamiento o preparación, a excepción de lavado, corte, pelado o exprimido. Por ejemplo, las frutas, los frutos secos no transformados, vegetales, crustáceos y moluscos crudos, la miel, entre otros. ${ }^{119}$

Los alimentos moderadamente procesados son aquellos sometidos a un procesamiento relativamente simple, como los frutos secos o semi secos; nueces y semillas; alimentos envasados al vacío o alimentos de atmósfera controlada como ensaladas; alimentos congelados; la carne cruda; aceite de oliva virgen extra; frutas, verduras enlatadas en agua, salmuera, en su propio jugo; el té verde y manzanilla, etc. ${ }^{120}$

El grupo de los alimentos altamente procesados se subdividen en alimentos procesados básicos o de primera necesidad y alimentos altamente procesados. Son alimentos elaborados de forma industrial con métodos que implican alto grado de procesamiento, como el secado, la descamación, hidrogenación, tratamiento térmico, uso de aditivos y conservantes, y fritura industrial. Incluye productos que apenas requieren alguna o ninguna preparación doméstica, aparte de calentar y cocinar ${ }^{121}$. Son alimentos procesados básicos o de primera necesidad el pan, las pastas, el arroz, la leche, la mantequilla, los aceites vegetales. Se consideran alimentos altamente procesados la bollería industrial, galletas, cereales para el desayuno, el pan crujiente, la confitería, la carne y pescado procesado, el yogurt con frutas, entre otros. ${ }^{122}$

Por otro lado, El IFIC ordena a los alimentos según su grado de transformación en cinco categorías: alimentos mínimamente procesados, alimentos procesados para su conservación, mezclas de ingredientes combinados, alimentos listos para comer. ${ }^{123}$

Desde el punto de vista jurídico, en la legislación europea se distingue entre productos transformados y productos sin transformar. En el artículo 2, letra n) del Reglamento (CE) $\mathrm{n}^{\mathrm{o}}$ 852/2004 del Parlamento Europeo y del Consejo de 29 de abril de 2004, relativo a la higiene de los productos alimenticios se define a los productos sin transformar como aquellos

"productos alimenticios que no hayan sido sometidos a una transformación, incluyendo los productos que se hayan dividido, partido, seccionado, rebanado, deshuesado, picado, pelado o desollado, triturado, cortado, limpiado,

\footnotetext{
${ }^{116}$ Vid. MOUBARAC, Jean-Claude, et al.: "Food classification systems based on food processing: significance and implications for policies and actions: a systematic literature review and assessment". Current obesity reports, 2014, vol. 3, no 2, pág. 261.

${ }^{117}$ Vid. SLIMANI, N. et al.: "Contribution of highly industrially processed foods to the nutrient intakes and patterns of middle-aged populations in the European Prospective Investigation into Cancer and Nutrition study". European journal of clinical nutrition, 2009, vol. 63, pág. S208.

${ }^{118}$ El Consejo Internacional de Información Alimentaria (IFIC) en los que los ordena en: alimentos mínimamente procesados, alimentos procesados para su conservación, mezclas de ingredientes combinados, alimentos listos para comer. (véase EICHER-MILLER, Heather A.; FULGONI, Victor L.; KEAST, Debra R.: "Contributions of processed foods to dietary intake in the US from 2003-2008: a report of the Food and Nutrition Science Solutions Joint Task Force of the Academy of Nutrition and Dietetics American Society for Nutrition, Institute of Food Technologists, and International Food Information Council”. The Journal of nutrition, 2012, vol. 142, no 11, pág. 207

${ }^{119}$ Vid. SLIMANI, N. et al.: "Contribution of highly industrially processed foods to the nutrient intakes and patterns of middle-aged populations in the European Prospective Investigation into Cancer and Nutrition study". European journal of clinical nutrition, 2009, vol. 63, pág. S208.

${ }^{120}$ Vid. MOUBARAC, Jean-Claude, et al.: Op.Cit, pág. 262.

${ }^{121}$ Ibídem.

122 Ibídem.

${ }^{123}$ Vid. EICHER-MILLER, Heather; FULGONI, Victor; KEAST, Debra: "Contributions of processed foods to dietary intake in the US from 2003-2008: a report of the Food and Nutrition Science Solutions Joint Task Force of the Academy of Nutrition and Dietetics, American Society for Nutrition, Institute of Food Technologists, and International Food Information Council." The Journal of nutrition vol. 142, no 11, 2012.
}

Revista de Direito Brasileira | São Paulo, SP | v. 18 | n. 7 | p. 463 - 503 |Set./Dez. 2017 
desgrasado, descascarillado, molido, refrigerado, congelado, ultra congelado o descongelado". El artículo 2 letra o) ejusdem, define a los productos transformados como "productos alimenticios obtenidos de la transformación de productos sin transformar. Estos productos pueden contener ingredientes que sean necesarios para su elaboración o para conferirles unas características específicas".

Clasificar los alimentos desde el enfoque bromatológico según su grado de transformación o procesamiento, permite incluir a los productos procesados y altamente procesados dentro del resto de grupos que conforman los alimentos. No obstante, en realidad esta clasificación no satisface en absoluto los objetivos que se han planteado en esta investigación, puesto que no que queda claro qué diferencias existen entre los diversos grados de procesamiento; tampoco se puede determinar la naturaleza de los PSC, ni se pude medir el alcance que tienen para la salud el consumo de éstos.

En este sentido, se requiere el desarrollo de nuevos enfoques y marcos conceptuales acreditados y apropiados, que permitan el estudio y análisis de una clasificación de los alimentos desde la perspectiva del problema del sobrepeso y la obesidad.

El Centro de Estudios Epidemiológicos en Salud y Nutrición de la Escuela de Salud Pública de la Universidad de Sao Paulo (USP) en Brasil, dirigido por el Dr. MONTEIRO, ha desarrollado una clasificación de los alimentos a la que han llamado NOVA, ${ }^{124}$ cuyo propósito es la promoción de la salud y el bienestar, a través de la comprensión, prevención y control de la epidemia mundial de obesidad. $^{125}$

El enfoque de NOVA se aparta de los conceptos tradicionales que actualmente rigen la nutrición, que fundamentalmente la sitúa dentro del ámbito de las ciencias biológicas, la cual no responde adecuadamente a las circunstancias y al contexto de los entornos alimentarios en los que vivimos en la actualidad. ${ }^{126}$ "NOVA clasifica a los alimentos de acuerdo con el alcance y la finalidad de la elaboración de alimentos, en lugar de en términos de nutrientes; " 27 hace énfasis en el procesamiento de alimentos, que aunque en las últimas décadas se le ha prestado especial atención por su creciente importancia en el suministro de alimentos, su impacto en la modificación de los patrones dietéticos y la repercusión de éstos en la salud de las personas, no ha sido suficientemente estudiado; por lo que, de hecho el estudio del procesamiento de alimentos y sus efectos en la salud de las personas ha sido relegada como una cuestión secundaria. ${ }^{128}$

En la década de los 90, el equipo de investigadores de la USP observó que el aumento de la prevalencia de sobrepeso y la obesidad y algunas ENT relacionadas, que se venía produciendo en Brasil desde 1980, se habían convertido en el problema más importante de salud pública para el país, sin que se hubiesen producido cambios específicos en el consumo de nutrientes o alimentos. ${ }^{129}$ El grupo de investigadores de la USP observó por ejemplo que no se había producido un aumento en el consumo de grasa o azúcar. De hecho, este mismo fenómeno parece ser un patrón mundial, puesto que se observó el mismo modelo de comportamiento en los países donde la prevalencia de la obesidad aumentó, siendo que el porcentaje de energía

\footnotetext{
${ }^{124}$ Vid. MONTEIRO Carlos; et al.: NOVA. "The star shines bright. [Food classification." Public health] World Nutrition January-March 2016, 7, pág.28.

125 Vid. MONTEIRO, Carlos, et al.: WN The Food System. World, 2012, vol. 3, no 12. pág. 528.

${ }^{126}$ Ibídem.

127 Vid. MONTEIRO Carlos, et al.: "NOVA. The star shines bright. [Food classification." Public health] World Nutrition January-March 2016, 7, pág.28.

${ }^{128}$ Vid. Ibídem.

${ }^{129}$ Vid. MONTEIRO, Carlos, et al.: WN The Food System. World, 2012, vol. 3, no 12. pág. 529.
} Revista de Direito Brasileira | São Paulo, SP | v. 18 | n. 7 | p. 463 - 503 | Set./Dez. 2017 
consumida en forma de grasa se redujo de 38\% a 34\% entre $1976-1980$ y $1988-1991{ }^{130}$ En su lugar, sí se observó un claro aumento del consumo de distintos tipos de productos alimenticios y bebidas procesadas (como refrescos, galletas y ciertos tipos de productos cárnicos grasos procesados como salchichas y hamburguesas). ${ }^{131}$ El grupo notó que a pesar de las aparentes diferencias que existían entre los productos procesados, éstos poseían ciertas propiedades en común, como que eran alimentos ya preparados o listos para comer, energéticamente densos, grasos, con cantidades considerables de azúcar y/o sal añadidas y formulados para tener propiedades de híper palatabilidad.

Para el grupo de investigación, esto sugería que la importancia del consumo de grasa o azúcar no debía medirse de forma aislada, sino cuando están contenidas y/o combinación con ciertos productos alimentarios. A su vez esto sugiere que el foco de análisis no debe concentrarse en los nutrientes o en los alimentos como tales, sino sobre los tipos de productos, en este caso procesados, que pudieran clasificarse dentro un solo grupo. Es decir, que este tipo de producto que en principio no comparte ninguna característica en común, en realidad poseen unas "propiedades" comunes que les permiten ser clasificados como un grupo especial; dichas propiedades son, productos preparados o listos para comer, energéticamente densos, grasos, con cantidades considerables de azúcar y/o sal añadidas y formulados para tener propiedades de híper palatabilidad. A raíz de estos hallazgos, el grupo de la USP desarrolló un nuevo marco conceptual, basado en una nueva clasificación en los que se divide a los alimentos en cuatro grupos: 1) alimentos no elaborados o mínimamente procesados; 2) ingredientes culinarios; 3) alimentos procesados; y 4) bebidas y productos alimentarios ultra procesados ${ }^{132}$.

GRUPO 1: Los alimentos no elaborados o mínimamente procesados son aquellos que han sido alterados por procesos como la eliminación de partes no deseadas, secado, trituración, molienda, fraccionamiento, filtrado, asado, hervido, pasteurización, refrigeración, congelación, colocación en contenedores, envasado al vacío, o fermentación no alcohólica. Es importante destacar que mediante estos procesos no se añade ningún tipo de sustancias como sal, azúcar, aceites o grasas ${ }^{133}$

GRUPO 2: Los ingredientes culinarios son sustancias obtenidas directamente de los alimentos del grupo 1 o de la naturaleza por procesos tales como prensado, refinación, trituración, molienda y secado por pulverización. Rara vez se consumen en ausencia de alimentos del grupo 1 . $^{134}$

GRUPO 3: Los alimentos procesados son aquellos que se producen a partir de procesos que consisten en la adición de azúcar, aceite, sal u otras sustancias del grupo 2 a alimentos del grupo 1, que incluyen varios métodos de preservación o cocción. La mayoría de alimentos procesados tienen dos o tres ingredientes. El objetivo principal de la fabricación de alimentos

\footnotetext{
${ }^{130}$ Vid. DREWNOWSKI, Adam; SPECTER:" Poverty and obesity: the role of energy density and energy costs". The American journal of clinical nutrition, 2004, vol. 79, no 1, pág.13.

${ }^{131}$ Ibídem, pág.530.

132 Vid. MONTEIRO Carlos, et al. Op.Cit, pág.31.

${ }^{133} \mathrm{Se}$ incluyen en este grupo los alimentos frescos, exprimidos, refrigerados, congelados, frutas, verduras de hoja y hortalizas de raíz seca; arroz blanco, mazorca de maíz, leguminosas como los frijoles de todo tipo, lentejas, garbanzos; raíces y tubérculos como la patata y la yuca; hongos como setas frescas o secas; carnes, aves, pescados y mariscos, enteros o en forma de filetes, u otros cortes, refrigerados o congelados; huevos; leche pasteurizada o en polvo; jugos de frutas o vegetales frescos o pasteurizados sin adición de azúcar, edulcorantes o saborizantes; nueces de árboles y de tierra y otras semillas oleaginosas sin sal ni azúcar; especias como la pimienta, clavo y canela; yogur natural sin azúcar ni edulcorantes artificiales añadidos; té, café, agua potable, entre otros. Ibidem.

134 Ejemplos son la sal; azúcar y melaza obtenida de caña o de remolacha; la miel y el jarabe del árbol de arce; los aceites vegetales triturados a partir de aceitunas o de semillas; la mantequilla y la manteca de cerdo obtenidos de la leche y la carne del cerdo; almidones extraídos de maíz y otras plantas, entre otros Ibídem. pág.32.
} 
procesados es aumentar la durabilidad de los alimentos del grupo 1, o para modificar o mejorar sus cualidades sensoriales. ${ }^{135}$

GRUPO 4: Las bebidas y productos alimentarios ultra procesados son formulaciones industriales con cinco o más ingredientes, aunque por lo general son muchos más. Algunos de estos ingredientes también se utilizan en los alimentos procesados como azúcar, aceites, grasas, sal, antioxidantes, estabilizantes, y conservantes. También se hayan ingredientes que sólo se encuentran en los productos ultra procesados (cuyas sustancias no se utilizan comúnmente en preparaciones culinarias) así como aditivos cuyo propósito es imitar las cualidades sensoriales de los alimentos del grupo 1 o de preparaciones culinarias de estos alimentos, o para disfrazar cualidades sensoriales indeseables del producto final. Los alimentos del grupo 1 se encuentran en una pequeña proporción del producto ultra procesado o incluso simplemente pueden no estar presentes en éstos. ${ }^{136}$

Existen sustancias que sólo se encuentran en los productos ultra procesados que han sido extraídas de alimentos como la caseína, la lactosa, el suero de leche, y el gluten; algunos derivados de su posterior procesamiento de los constituyentes de los alimentos, como aceites hidrogenados o interesterificados, las proteínas hidrolizadas, proteína de soja aislada, maltodextrina, azúcar invertido y jarabe de maíz de alta fructosa. Las clases de aditivos que sólo se encuentran en los productos ultra procesados incluyen colorantes, estabilizadores de color, aromas, potenciadores del sabor, edulcorantes distintos del azúcar, y auxiliares tecnológicos tales como carbonatación, reafirmante, aumento de volumen y anti aumento de volumen, de espuma, anti apelmazamiento y acristalamiento, emulsionantes, secuestrantes y humectantes.

El objetivo principal de ultra-procesamiento industrial es crear productos que estén listos para comer, beber o calentar, que puedan sustituir tanto a los alimentos procesados como a los mínimamente procesados. ${ }^{137}$

La clasificación de alimentos NOVA supone un importante avance para ayudar a comprender cuál es el impacto del consumo de los productos ultra procesados en la prevalencia de la ESO. Su contribución ha sido reconocida por la $\mathrm{FAO}^{138}$ y la $\mathrm{OMS}^{139}$ al incorporar respectivamente estos nuevos conceptos en sus guías y recomendaciones. El aporte más significativo de esta nueva forma de clasificar a los alimentos consiste en mostrar la naturaleza de éstos a través de cómo son trasformados y procesados y no sólo si lo son o no. La clasificación NOVA permite distinguir con claridad entre los alimentos procesados y los utra procesados, revelando con qué cantidad de alimento en realidad están hechos estos productos y facilitando a las personas poder elegir opciones más sanas y naturales.

\footnotetext{
${ }^{135}$ Se encuentran entre este grupo de alimentos las verduras, frutas o legumbres enlatadas; nueces o semillas saladas o en confite; carnes saladas, curadas o ahumadas; pescado enlatado; frutas en almíbar; quesos y panes recién hechos sin envasar. Se incluye en este grupo la cerveza, el vino y la sidra por ser productos del grupo 1 producidos por fermentación. Los alimentos procesados pueden contener aditivos utilizados para preservar sus propiedades originales o para resistir la contaminación microbiana. Ibídem.

136 Ibídem.

${ }^{137}$ Ejemplos de productos ultra-procesados son las bebidas carbonatadas; aperitivos envasados (dulces o salados); los helados, el chocolate, los caramelos; los panes y bollos envasados; las margarinas y productos para untar; las galletas, pasteles, tartas, y mezclas para pasteles; desayunos a base de "cereales", y barras "energéticas"; bebidas energizantes; bebidas a base de leche, yogures de "frutas", bebidas de "frutas"; bebidas de cacao; extractos de carne y pollo y salsas instantáneas; fórmulas lácteas infantiles y otros productos para bebés; productos para adelgazar como sustitutivos de comidas y platos fortificadas; productos listos para calentar que incluyen pasteles precocinados, platos de pasta, y pizza; nuggets y croquetas de ave corral y pescado; salchichas, hamburguesas, perritos calientes, y otros productos cárnicos reconstituidos; sopas enlatadas o deshidratadas, postres, sopas y fideos empaquetados "instantáneos"Ibídem.

${ }^{138}$ Vid. Food and Agriculture Organization of the United Nations. Guidelines on the collection of information on food processing through food consumption surveys. Rome: FAO, 2015.

${ }^{139}$ Vid. Pan American Health Organization. Ultra-Processed Food and Drink Products in Latin America: Trends, Impact on Obesity, Policy Implications. Washington DC: PAHO, 2015.
}

Revista de Direito Brasileira | São Paulo, SP | v. 18 | n. 7 | p. 463 - 503 | Set./Dez. 2017 


\subsection{Características problemáticas de los productos ultra procesados}

El marco conceptual propuesto a través de la clasificación NOVA, es el más adecuado para el estudio de las estrategias a abordar en la lucha contra la obesidad. En este sentido, nos basamos en los hallazgos y conclusiones del Centro de Estudios Epidemiológicos en Salud y Nutrición de la Escuela de Salud Pública de la Universidad de Sao Paulo, ${ }^{140}$ para analizar las características de los productos ultra procesados y posteriormente juzgar su naturaleza como alimentos y las consideraciones jurídicas que se deriven de ello.

El consumo de productos ultra procesados en todo el mundo no sólo está ampliamente generalizado, sino que está en aumento. ${ }^{141}{ }^{142}$ Este aumento se produce en detrimento del consumo de alimentos de los grupos 1, 2 y 3 de la clasificación $N O V A$, lo que en la práctica se traduce en una transición nutricional negativa que en los países desarrollados está consolidada, pero que en la mayoría del resto de países está en proceso de forma acelerada. En general se entiende que la transición nutricional aparece como consecuencia del desarrollo económico, la cual empuja a la población de un país determinado a pasar de un estado de desnutrición a un estado de sobrealimentación, como resultado de cambiar sus preferencias alimentarias tradicionales (que consisten en dietas a base de platos preparados en el hogar, bajos en sal, índices glucémicos bajos y energéticamente equilibrados) por dietas occidentales menos saludables y complejas fundamentalmente a base de productos ultra procesados, que conducen a la obesidad y enfermedades no transmisibles asociadas. ${ }^{143}$

No obstante, a pesar de que en la literatura científica sólo se considere la transición nutricional como un proceso dañino y perjudicial para las poblaciones humanas que la experimentan, relacionada directamente con la prevalencia de la ESO, ${ }^{144} 145146$ en realidad una transición nutricional no es más que un cambio brusco de patrones en las costumbres, hábitos y preferencias alimentarias que pueden ser cuantitativos como cualitativos. ${ }^{147}$ En este sentido, este cambio puede ser negativo o positivo; es decir, se pueden experimentar transiciones nutricionales negativas, como el ejemplo que se ha citado antes. Pero puede ocurrir que se invierta el proceso al corregir los elementos disrruptores de los sistemas alimentarios, mediante la aplicación de políticas alimentarias correctivas acertadas y un marco jurídico eficaz que regule y racionalice los sistemas alimentarios, con el objeto de propiciar un proceso de transición nutricional positiva. En el caso que se plantea en esta investigación, a mayor grado de transición nutricional negativa y posterior consolidación de ésta, mayor es la prevalencia de la ESO.

\footnotetext{
${ }^{140}$ En la actualidad el marco conceptual que propone la clasificación NOVA es tomado como referente en la investigación sobre los temas relacionados con la epidemia de sobrepeso y obesidad.

${ }^{141}$ Vid. STUCKLER, David; NESTLE, Marion: “Big food, food systems, and global health”. PLoS Med, 2012 , vol. 9, no 6, pág. e1001242.

${ }^{142}$ Vid. MOODIE, Rob, et al.: "Profits and pandemics: prevention of harmful effects of tobacco, alcohol, and ultraprocessed food and drink industries". The Lancet, 2013, vol. 381, no 9867, pág. 671.

${ }^{143}$ Vid. STUCKLER, David, et al.: "Manufacturing epidemics: the role of global producers in increased consumption of unhealthy commodities including processed foods, alcohol, and tobacco". PLoS Med, 2012, vol. 9, no 6, pág. e1001235

${ }^{144}$ Vid. WHO. Global status report on noncommunicable diseases 2010. Description of the global burden of NCDs, their risk factors and determinants. April, 2011. Report. Geneva: World Health Organization, 2011. pág. 2, 20, 52, 86.

${ }^{145}$ Vid. MOODIE, Rob, et al.: "Profits and pandemics: prevention of harmful effects of tobacco, alcohol, and ultraprocessed food and drink industries". The Lancet, 2013, vol. 381, no 9867, pág. 671.

${ }^{146}$ Vid. ASTRUP, Arne, et al.: "Nutrition transition and its relationship to the development of obesity and related chronic diseases". Obesity Reviews, 2008, vol. 9, no s1, pág. 48.

${ }^{147}$ Vid. Dieta, O. M. S. (2003). nutrición y prevención de enfermedades crónicas. Informe de una Consulta Mixta de Expertos OMS/FAO. OMS, Serie de Informes Técnicos, 916. pág.24.
}

Revista de Direito Brasileira | São Paulo, SP | v. 18 | n. 7 | p. 463 - 503 |Set./Dez. 2017 
Existe por tanto suficiente evidencia que relaciona el consumo de los productos ultra procesados con la ESO. ${ }^{148} 149150 \quad 151 \quad 152$ Esta relación se debe a que los productos ultra procesados presentan una serie de características problemáticas que repercuten negativamente en la dieta y hábitos alimentarios de las personas y por consiguiente en su salud.

La revisión de la literatura científica sugiere que las características problemáticas de los productos ultra procesados no son sólo de carácter nutricional, sino también metabólica, socioeconómica y ambiental. ${ }^{153}$ En este sentido, se ha encontrado que las principales características de los ultra procesados que suponen un problema para la salud que están relacionados con la ESO son las siguientes: ${ }^{154}$ a) Son nutricionalmente desequilibrados, son energéticamente densos; b) son híper apetecibles; c) desplaza el consumo de los alimentos saludables; d) son imitaciones de alimentos; e) son falsamente percibidos como saludables; f) son promocionados a través de estrategias de marketing agresivo.

a) Son nutricionalmente desequilibrados: Son productos que se caracterizan por contener grandes cantidades de sal, grasas saturadas, ácidos grasos trans y azúcar añadida. ${ }^{155156157}$ Por el contrario son deficientes o carecen totalmente de proteínas y/o fibra, dos componentes que pueden mejorar la sensación de saciedad y contribuyen a la absorción lenta de componentes, como el azúcar en sangre. ${ }^{158}$ Por otro lado, suelen contener gran cantidad de aditivos cuya seguridad se desconoce o es controvertida, ya sea de forma individual o por sus combinaciones entre sí.

b) Son energéticamente densos: La densidad energética de un alimento se define como la cantidad de energía o calorías disponibles en un alimento por unidad de peso (Kcal/gr). ${ }^{159}$ Debido a que los productos ultra procesados se componen fundamentalmente de ingredientes hipercalóricos y que carecen de fibra y agua (cuando son sólidos) su densidad de energía varía de bastante alta (de 225-275 Kcal/gr, como es el caso del pan), a alto (de 350 a $400 \mathrm{Kcal} / \mathrm{gr}$, que es la que suelen tener las barritas energéticas) a muy alta (400-500 Kcal/gr para la mayoría de las galletas y las patatas fritas/chips). ${ }^{160}$ Además de ser energéticamente densos y nutricionalmente desequilibrados, los productos ultra procesados están diseñados para ser híper apetecibles, por lo que es difícil controlar su

\footnotetext{
${ }^{148}$ Vid. STUCKLER, David; NESTLE, Marion: "Big food, food systems, and global health". PLoS Med, 2012, vol. 9, no 6, pág. e1001242.

${ }^{149}$ Vid. MONTEIRO, C. A.: "The big issue is ultra-processing. There is no such thing as a healthy ultra-processed product.[Commentary]". Journal of the World Public Health Nutrition Association, 2011, vol. 7, pág. 344.

${ }^{150}$ Vid. PEREIRA, Mark A. et al.: 'Fast-food habits, weight gain, and insulin resistance (the CARDIA study): 15year prospective analysis". The lancet, 2005, vol. 365, no 9453, pág. 36.

151 Vid. MONDIALE DE LA SANTÉ, Organisation. Interim Report of the Commission on Ending Childhood Obesity. Genève: OMS, 2015. pág. 9.

${ }^{152}$ Vid. ONETE, Bogdan Cristian, et al.: "Researching the gap between foodstuff's attractiveness and real nutritional profile-prerequisite for strengthening nutrition education and consumer rights protection". Amfiteatru Economic, 2014, vol. 16, no 36, pág. 481.

${ }^{153}$ Vid. MONTEIRO C, CANNON G, LEVY RB, Claro RM, MOUBARAC J-C.: The Food System. The big issue. [Position paper] World Nutrition December 2012, 3, 12. pág. 558- 560.

${ }^{154}$ Tomado del trabajo del grupo de investigación del Centro de Estudios Epidemiológicos en Salud y Nutrición de la Escuela de Salud Pública de la Universidad de Sao Paolo.

${ }^{155}$ Vid. MONTEIRO C, et al Ibidem.

${ }^{156}$ Vid. MOODIE, Rob, et al.: "Profits and pandemics: prevention of harmful effects of tobacco, alcohol, and ultraprocessed food and drink industries". The Lancet, 2013, vol. 381, no 9867, pág. 671

${ }^{157}$ Vid. LUDWIG, David S.: Technology, diet, and the burden of chronic disease. JAMA, 2011, vol. 305, no 13, pág. $1352-1353$.

158 Ibídem

159 Vid. DREWNOWSKI, Adam:"Obesity and the food environment: dietary energy density and diet costs".American journal of preventive medicine, 2004, vol. 27, no 3, pág. 154.

${ }^{160}$ Vid. MONTEIRO Carlos: World Nutrition December 2012, 3, 12. pág. 559.
}

Revista de Direito Brasileira | São Paulo, SP | v. 18 | n. 7 | p. 463 - 503 | Set./Dez. 2017 
ingesta y por consiguiente el aumento de peso corporal. ${ }^{161} \mathrm{El}$ hecho de que sean baratos hacen que sean muy accesibles para los consumidores, lo que agrava aún más el problema. De hecho se observa una relación inversa entre la densidad energética de los alimentos y el costo de energía (\$/klca), lo que significa que las dietas basadas en granos refinados, azúcares añadidos y grasas añadidas; es decir, los productos ultra procesados, son más asequibles que las dietas recomendadas a base a carnes magras, pescado, verduras frescas y frutas. ${ }^{162} \mathrm{El}$ hecho de que los alimentos ricos en energía cuesten menos de producir por Kcal que los alimentos ricos en nutrientes (a la industria le cuesta aproximadamente dos dólares obtener $40.000 \mathrm{kcal}$ de los azúcares y grasas añadidos) quiere decir que las dietas hipercalóricas no sólo son más baratas, sino que son susceptibles de ser seleccionadas preferentemente por el consumidor de bajos ingresos, ${ }^{163}$ lo que hace del problema de la obesidad un problema también de carácter social. La epidemia de obesidad tiene una prevalencia más elevada en las clases sociales más bajas, independientemente de si se trata de países desarrollados o no.

c) Son híper apetecibles: Los productos ultra procesados están diseñados deliberadamente para que una vez consumidos por primera vez, las personas sientan la necesidad impulsiva de tener que volver a consumirlos. Estos productos están diseñados a partir del concepto de Bliss Point, que consiste en la combinación apropiada de azúcar, sal y grasa con la intención de crear productos híper apetecibles, capaces de producir efectos adictivos en las personas, al estimular los sistemas de recompensa del cerebro de forma muy parecida a lo que ocurre con las drogas. ${ }^{164} 165$ El concepto de Bliss Point fue desarrollado por HOWARD MOSKOWITZ en la década de los 70, ${ }^{166}$ para mejorar las raciones de comida deshidratada de los soldados de los Estados Unidos, que eran tan poco apetitosas que le llamaban asesinas del apetito. En la década de los 80, General Food contrató a MOSKOWITZ para "mejorar" sus productos y el resto de compañías utilizaron el mismo concepto. A partir de entonces es una práctica habitual y generalizada de la industria alimentaria. Con la cantidad adecuada de azúcar, sal y grasa la industria no sólo consigue disfrazar cualquier sustancia incomible y por supuesto nada nutritiva, y convertirlo en un producto híper apetecible, que es la forma de conseguir lo que, la industria, el Codex, y la legislación europea llama calidad alimentaria. Además, contribuye a la creación de preferencias alimentarias que pueden llegar a ser adictivas. Debido a su formulación hecha a base de azúcar, sal y grasas, presentan altas cargas glucémicas susceptibles de trastornar el sistema digestivo y las señales de saciedad que trasmite el cerebro, produciendo de forma pasiva una excesiva ingesta de energía. ${ }^{167}$

d) Desplaza el consumo de los alimentos saludables: Los productos ultra procesados se caracterizan por ser productos convenientes o ready to eat, que consisten en platos o productos envasados listos para consumir o para preparar de forma rápida y sencilla. ${ }^{168}$ Además, la mayoría de ellos pueden ser consumidos en cualquier sitio y no requieren de

161 Vid. ROBERTO, Christina A. et al.: "Patchy progress on obesity prevention: emerging examples, entrenched barriers, and new thinking". The Lancet, 2015, vol. 385, no 9985, pág. 2405.

162 Vid. DREWNOWSKI, Adam: "Obesity and the food environment: dietary energy density and diet costs". American journal of preventive medicine, 2004, vol. 27, no 3, pág. 154.

${ }^{163}$ Vid. DREWNOWSKI, Adam: "The real contribution of added sugars and fats to obesity". Epidemiologic reviews, 2007, vol. 29, no 1, pág. 160, 166.

${ }^{164}$ Vid. N GEARHARDT, Ashley, et al.: "The addiction potential of hyperpalatable foods". Current drug abuse reviews, 2011, vol. 4, no 3, pág. 144.

${ }^{165}$ Se analizará las propiedades adictivas de los productos ultra procesados en el capítulo III, en el apartado sobre las vulnerabilidades del consumidor.

${ }^{166}$ Vid. MOSS, Michael. Salt, sugar, fat: how the food giants hooked us. Random House, 2013. pág. 54.

${ }^{167}$ Vid. MONTEIRO Carlos: World Nutrition December 2012, 3, 12. pág. 559.

${ }^{168}$ Vid. SMITH, Andrew F.: Fast Food and Junk Food: An Encyclopedia of What We Love to Eat [2 volumes]: An Encyclopedia of What We Love to Eat. ABC-CLIO, 2011. pág. 153.

Revista de Direito Brasileira | São Paulo, SP | v. 18 | n. 7 | p. 463 - 503 |Set./Dez. 2017 
platos o cubiertos. Si a eso se le suma que son productos híper apetecibles y baratos, la consecuencia resulta obvia: el consumo de alimentos equilibrados, ricos en nutrientes y fibra se ve desplazado por el consumo de los productos ultra procesados. ${ }^{169}$ El desplazamiento del consumo de productos alimentarios tradicionales equilibrados y nutritivos, por los productos ultra procesados energéticamente densos, etc. ${ }^{170}$ constituyen de hecho, por un lado la evidencia de la materialización de lo denominado como transición nutricional negativa; y por otro lado, la evidencia del daño que produce el consumo de estos productos a la salud pública, ${ }^{171}$ concretamente en lo concerniente con la prevalencia de sobrepeso, obesidad y síndrome metabólico. ${ }^{172}$

e) Son imitaciones de alimentos: Los alimentos procesados son aquellos que se producen a partir de procesos que consisten en la adición de azúcar, aceite, sal u otras sustancias que incluyen varios métodos de preservación o cocción, no suelen tener más de dos o tres ingredientes y su objetivo principal es aumentar la durabilidad de los alimentos sin procesar para modificarlos o mejorar sus cualidades sensoriales. ${ }^{173}$ Lo productos ultra procesados en cambio, son producidos a partir de formulaciones que totalmente o en gran parte se componen de sustancias derivadas de alimentos, que por lo general contienen pocos o ningún alimento entero; por lo tanto sus ingredientes no son reconocibles como versiones de alimentos, aunque el producto final pueda imitar la apariencia, forma y cualidades sensoriales de estos, no así su composición nutricional. ${ }^{174}$ La mimetización de las sustancias de las que se componen los productos ultra procesados en alimentos reales, manipula la percepción de la personas, mermando considerablemente su capacidad para hacer elecciones de dietas saludables. Numéricamente, la mayoría de los ingredientes de los ultra procesados son aditivos, como conservantes, estabilizadores, emulsificantes, solventes, aglutinantes, cohesionantes, aumentadores de volumen, endulzantes, resaltadores sensoriales, colorantes y saborizantes, y auxiliares para el procesamiento, muchos de los cuales no están disponibles para el público general en la tiendas o supermercados. Para modificar su volumen se les suele agregar aire o agua. ${ }^{175}$ Los platos preparados, como los que se venden congelados, aparentan ser alimentos procesados elaborados a partir de alimentos enteros del grupo 1 e ingredientes culinarios del grupo 2, pero en realidad no son más que mezclas de sustancias obtenidas de alimentos refinados o derivados de los constituyentes de los alimentos, con poca o ninguna cantidad de alimentos, que a menudo contienen saborizantes, colorantes y otros aditivos que imitan o intensifican las cualidades sensoriales de los alimentos o preparaciones culinarias a base de alimentos. "Por naturaleza, los productos ultra procesados no son "alimentos modificados" ni son otras versiones de los alimentos, sino que sus formulaciones a menudo emplean tecnologías dirigidas a imitar la apariencia, forma y cualidades

${ }^{169}$ Vid. BROWNELL, Kelly D.; HORGEN, Katherine Battle: Food fight: The inside story of the food industry, America's obesity crisis, and what we can do about it. Chicago: Contemporary books, 2004, pág. 10.

${ }^{170}$ Vid. WORLD HEALTH ORGANIZATION. Technical Report Series 894. Obesity: preventing and managing the global epidemic. World Health Organization, 2000, pág. 190.

${ }_{171}$ Vid. MONTEIRO, Carlos A. et al.: "Ultra-processed products are becoming dominant in the global food system". Obesity reviews, 2013, vol. 14, no S2, pág. 26.

${ }^{172}$ Vid. TAVARES, Letícia Ferreira, et al.: "Relationship between ultra-processed foods and metabolic syndrome in adolescents from a Brazilian Family Doctor Program”. Public health nutrition, 2012, vol. 15, no 01, pág. 82.

${ }^{173}$ Vid. MONTEIRO, Carlos A. et al.: NOVA...... pág. 32.

${ }^{174}$ Vid. Alimentos y bebidas ultraprocesados en América Latina: tendencias, efecto sobre la obesidad e implicaciones para las políticas públicas. http://iris.paho.org/xmlui/handle/123456789/7698, consultado el 10 de junio de 2016, pág. 59.

${ }_{175}$ Ibídem.

${ }^{176}$ Vid. MONTEIRO, Carlos A. et al. Op. Cit, pág.32

Revista de Direito Brasileira | São Paulo, SP | v. 18 | n. 7 | p. 463 - 503 | Set./Dez. 2017 
sensoriales de los alimentos". ${ }^{177}$ Los productos ultra procesados son sustancias sintéticas comestibles, que artificialmente aparentan ser alimentos.

f) Son falsamente percibidos como saludables: Se ha demostrado que los productos ultra procesados son por naturaleza poco saludables. ${ }^{178}$ La industria lo sabe y es consciente que las personas están cada vez más y mejor informadas e interesadas en lo que come. Por esta razón la industria alimentaria se esfuerza por desarrollar nuevos productos que sean percibidos como saludables, a los que les llama "alimentos funcionales," que en el mejor de los casos son en realidad un poco menos malos. Para conseguir que los ultra procesados sean falsamente percibidos como saludables, se les fortifica con fibra sintética, vitaminas, minerales y/o algún ingrediente que por sí solo y de forma aislada pueda tener alguna propiedad saludable, por los que en ese caso, se le permite a la industria hacer declaraciones de propiedad saludables o Health Claims. ${ }^{179}$ El problema que se observa con los "alimentos" funcionales y con los Claims, es que en general siguen siendo energéticamente densos, pero al permitirse hacer declaraciones de propiedad saludables sobre alguno de sus componentes, la personas perciben erróneamente que son saludables. Esto repercute en un consumo excesivo de estos productos, que a su vez implica remplazar las comidas hechas a base de alimentos reales por éstos, lo cual tiene un impacto directo en el aumento de la prevalencia de la ESO:

“...los productos ultra-procesados 'saludables' son responsables de acelerar la sustitución de los alimentos enteros, frescos o mínimamente procesados, así como la pandemia de la obesidad. Este es y debe ser un asunto de gran preocupación para todos los interesados en la nutrición y la salud pública, incluyendo líderes en el sistema de las Naciones Unidas y los gobiernos nacionales." $" 180$

g) Son promocionados a través de estrategias de marketing agresivo: Los productos ultra procesados son altamente rentables, con grandes márgenes de beneficios para las empresas que los producen, en su mayoría grandes corporaciones internacionales, que les permite gastarse enormes cantidades de dinero en promocionar sus productos a través técnicas de marketing agresivos. ${ }^{181} 182$ Estos productos son promocionados inversamente proporcional con respecto a las recomendaciones nutricionales de consumo de los alimentos frescos y enteros. Se calcula que al año la industria alimentaria mundial se gasta 30 mil millones de dólares en promocionar en su inmensa mayoría productos alimentarios nada saludables. ${ }^{183}$ Los recursos empleados en la promoción de estos productos evidencian que el marketing funciona, por lo que la industria vende más, y la

\footnotetext{
${ }^{177}$ Cfr. Alimentos y bebidas ultraprocesados en América Latina: tendencias, efecto sobre la obesidad e implicaciones para las políticas públicas. http://iris.paho.org/xmlui/handle/123456789/7698, consultado el 10 de junio de 2016, pág. 8.

${ }^{178}$ Ibídem.

${ }^{179}$ Vid. MONTEIRO Carlos: "The Food System. Ultra-processing. The big issue for nutrition, disease, health, wellbeing”. World Nutrition, 3, 12. December 2012.3, 12. pág. 560.

180 Traducción propia: “...ultra-processed products are liable to accelerate the replacement of whole, fresh or minimally processed foods, and also the obesity pandemic. This is and should be a matter of great concern to all concerned with nutrition and public health, including leaders in the United Nations system and national governments." Véase MONTEIRO Carlo: "The big issue is ultra-processing. There is no such thing as a healthy ultra-processed product." . World Nutrition August 2011, 2, 7, pág.336.

${ }^{181}$ Vid. Monteiro C, Cannon G, Levy RB, Claro RM, Moubarac J-C . The Food System. The big issue. [Position paper] World Nutrition December 2012, 3, 12, 560.

${ }^{182}$ Vid. STUCKLER, David; NESTLE, Marion: "Big food, food systems, and global health." PLoS Med, 2012 , vol. 9, no 6, pág. e1001242

${ }^{183}$ Cfr. BROWNELL, Kelly D.; HORGEN, Katherine Battle. Food fight: The inside story of the food industry, America's obesity crisis, and what we can do about it. Chicago: Contemporary books, 2004, pág.103.
}

Revista de Direito Brasileira | São Paulo, SP | v. 18 | n. 7 | p. 463 - 503 |Set./Dez. 2017 
gente consume más productos ultra procesados en lugar de los alimentos tradicionales. El Target suelen ser niños y adolescentes, minorías raciales o las clases de ingresos económicos bajos. ${ }^{184} 185$

\subsection{Naturaleza de los Productos ultra procesados como producto alimentario y consideraciones jurídicas}

En el apartado anterior al analizar las características problemáticas de los productos ultra procesados, se pudo determinar que éstos no son alimentos propiamente dichos, sino que son imitaciones de alimentos: sustancias "semi-inocuas" (puesto que su composición nutricional pueden representar un riesgo para la salud) comestibles y nutricionalmente pobres, compuestas por una gran cantidad de aditivos y conservantes, que para hacerlos agradables al gusto (o sea, comibles) se les añade sal, azúcar y grasas en cantidades que les convierten en sustancias hipercalóricas, baratos de producir y convenientes. Si bien es cierto que el consumo ocasional de éstos productos no suponen un riesgo para la salud, ${ }^{186}$ la forma en que están formulados, el marketing agresivo y el resto de características problemáticas, en conjunción con entornos alimentarios tóxicos, hacen que sea muy difícil el consumo moderado u ocasional. La tecnología alimentaria actual es capaz de dar forma y apariencia a estas sustancias de modo que incluso imiten las cualidades sensoriales de los alimentos. De hecho, para la mayoría de personas, un producto ultra procesado es un alimento, como lo podría ser cualquier plato tradicional preparado con alimentos del grupo 1 y con ingredientes culinarios del grupo 2 de la clasificación NOVA. No obstante, no lo son; ni siquiera son modificaciones de alimentos, ni tampoco versiones de alimentos diferentes. ${ }^{187}$ Algunos, como BIRCH les consideran simplemente alimentos inferiores. $^{188}$

Ahora bien, ¿si los productos ultra procesados no son alimentos, entonces qué son?, porque además de imitar a los alimentos en apariencia y en otras características organolépticas, también se ingieren como éstos y llegan a satisfacer ciertas necesidades biológicas y sociales igual que éstos; aunque ciertamente poseen ciertas características que les hacen diferir de los alimentos, como la adicción, las altas cargas glucémicas y su desequilibrio nutricional. Para nosotros, un producto ultra procesado es fundamentalmente una sustancia comestible semiinocua producida a partir de productos sintéticos, no aptos para la dieta habitual del ser humano. ${ }^{189}$ Habiendo determinado la naturaleza de los productos ultra procesados, proponemso que se denominen Productos Sintéticos Consumibles o PSC.

Siendo que la naturaleza de los PSC es sintética y definitivamente no es un alimento, ¿deben por ello no ser considerados productos alimentarios? Los PSC sí deben considerarse productos alimentarios, aunque no productos alimenticios. Se distingue en el idioma castellano entre productos alimentarios y productos alimenticios. Se refiere en el caso de los primeros a un significado amplio que abarca todo lo que tenga ver con la alimentación. Se incluyen aquí todos

\footnotetext{
184 Vid. ROBERTO, Christina A. et al.: "Patchy progress on obesity prevention: emerging examples, entrenched barriers, and new thinking." The Lancet, 2015, vol. 385, no 9985, pág. 6.

185 Vid. YANCEY, Antronette K. et al.: “A cross-sectional prevalence study of ethnically targeted and general audience outdoor obesity-related advertising." Milbank Quarterly, 2009, vol. 87, no 1, pág. 177.

${ }^{186}$ Vid. MONTEIRO Carlos: World Nutrition December 2012, 3, 12. pág. 337.

187 Vid. Alimentos y bebidas ultra procesados en América Latina: tendencias, efecto sobre la obesidad e implicaciones para las políticas públicas. http://iris.paho.org/xmlui/handle/123456789/7698, consultado el 10 de junio de 2016, pág. 8.

${ }^{188}$ Vid. BIRCH, Leann L:“Development of food preferences”. Annual review of nutrition, 1999, vol. 19, no 1, pág. 43.

189 Inocuidad implica que un producto es seguro; es decir, que no causa daño. En el caso de los PSC deben considerarse como sustancias semi-inocuas, puesto que efectivamente en condiciones normales no produce ningún daño si se consume alguna de forma esporádica, pero sí si su consumo es habitual y prolongado.
} 
los elementos y procesos involucrados en la transformación y procesamiento de los alimentos como las partes de los animales criados y sacrificados para el consumo humano, la leche, las frutas y verduras y en general todos los alimentos del grupo 1, 2 y 3 de la clasificación NOVA; así como también los productos que de éstos se obtengan; los envases que los contienen y los materiales que están en contacto con éstos; incluso la materia prima con la que están elaborados los piensos y los piensos mismos para animales destinados para el consumo humano. Por otro lado, los productos alimenticios tienen un significado más restringido, refiriéndose a aquellos que tienen la propiedad de alimentar; o sea, de nutrir. En este sentido, los PSC son esencialmente productos alimentarios cuya naturaleza sintética y desequilibrio nutricional les diferencia y aparta de los alimentos.

Ahora bien, a pesar que los PSC por su propia naturaleza no son alimentos, desde el punto de vista jurídico sí lo son. La concepción legal de alimento de la FAO establecida en el Codex Alimentarius es lo suficientemente amplia como para considerar alimento no sólo a los PSC, sino también a las sustancias que se utilizan en la fabricación, preparación o tratamiento de los alimentos por el hecho de que éstas o cualquier otra, esté destinada para el consumo humano:

“...toda sustancia, elaborada, semielaborada o bruta, que se destina al consumo humano, incluyendo las bebidas, el chicle y cualesquiera otras sustancias que se utilicen en la fabricación, preparación o tratamiento de los alimentos, pero no incluye los cosméticos ni el tabaco ni las sustancias utilizadas solamente como medicamentos." 190

En el caso de la legislación europea ocurre exactamente lo mismo, "se entenderá por «alimento» (o «producto alimenticio») cualquier sustancia o producto destinados a ser ingeridos por los seres humanos o con probabilidad razonable de serlo, tanto si han sido transformados entera o parcialmente como si no." 191

Estas son algunas de las sustancias que se encuentran en los PSC que según la definición de alimento del Codex Alimentarius y el Reglamento ${ }^{\circ}$ 178/2002 son considerados como tal: COLORANTES: E100 Curcumina, E101 Riboflavina, E102 Tartrazina, E104 Amarillo de quinoleína, E120 ácido carmínico, E122 Azorrubina, E123 Amaranto, E127 Eritrosina, E129 Rojo Allura AC, E131 Azul patente V, E132 Indigotina, E133 Azul brillante FCF, E140 Clorofilas; EDULCORANTES: E420 Sorbitoles, E421 Manitol, E950 Acesulfamo K, E951 Aspartamo, E952 Ciclamatos, E953 Isomaltosa, E954 Sacarinas, E955 Sucralosa, E957 Taumatina, E959 Neohesperidina DC, E961 Neotamo, E962 Sal de aspartamo y acesulfamo, E965 Maltitoles, E966 Lactitol; aditivos distintos de los colorantes y edulcorantes: E170 Carbonato de calcio, E200 Ácido sórbico, E202 Sorbato potásico, E203 Sorbato cálcico, E214 phidroxibenzoato de etilo, E215 p-hidroxibenzoato sódico de etilo, E218 p-hidroxibenzoato de metilo, E219 p-hidroxibenzoato sódico de metilo, E220 Dióxido de azufre, E221 Sulfito de sodio, E222 Sulfito ácido de sodio, E223 Metabisulfito sódico. ${ }^{192}$

Evidentemente estas sustancias no son alimentos, aunque deba considerárseles como tal por mandato legal. Aunque la ley afirme que son alimentos, cualquier persona o consumidor

\footnotetext{
${ }^{190}$ Vid. ALIMENTARIUS, CODEX. Comisión del Codex Alimentarius. Manual de Procedimiento. 2011. pág. 22

${ }^{191}$ Cfr. EUROPEAS, Comunidades. Reglamento (CE) no 178/2002 del Parlamento Europeo y del Consejo del 28 de enero de 2002 por el que se establecen los principios y los requisitos generales de la legislación alimentaria, se crea la Autoridad Europea de Seguridad Alimentaria y se fijan procedimientos relativos a la seguridad alimentaria. Diario of. Comunidades eur, 2002. Artículo 2.

${ }^{192}$ Vid. EU COMMISSION, et al.: Commission Regulation (EU) No 1129/2011 of 11 November 2011 amending Annex II to Regulation (EC) No 1333/2008 of the European Parliament and of the Council by establishing a Union list of food additives. Official Journal of the European Union L, 2011, vol. 295, no 4
} 
medio, ${ }^{193}$ incluso la mayoría de los niños no tendrían problema para saber diferenciar un alimento de alguna de estas sustancias en estado puro y aislada. Estas sustancias ni son comestibles por si solas, ni son apetitosas y ni siquiera tienen la apariencia de alimento; y por supuesto no nutren. No ocurriría lo mismo con una sustancia comestible, híper apetitosa y con apariencia de alimento; o sea, con un PSC, porque no se debe olvidar que un PSC es esencialmente poco más que la mezcla de varias de las sustancias de las mencionadas arriba, con un poco de sal, azúcar, grasa, y agua o aire. Adultos bien informados, niños y hasta expertos en nutrición podrían considerar a los ultra procesados como alimento y basar gran parte de su dieta en el consumo de éstos. Por tanto, resulta necesario una definición legal de alimento en la que, si bien no se excluya a los PSC como productos alimentarios que son, sí se diferencie y distinga suficientemente de los alimentos. El público necesita saber distinguir entre alimento y sustancia sintética comestible para que las personas puedan hacer decisiones de compra bien informada. Sólo entonces podrá esgrimirse la teoría de la responsabilidad individual como coartada para revertir la carga de la culpa de la Industria en la prevalencia de la ESO en las personas. ${ }^{194}$

\section{BIBLIOGRAFÍA}

ASTRUP, A. et al.: "Nutrition transition and its relationship to the development of obesity and related chronic diseases." Obesity Reviews, 2008, vol. 9, no s1.

BIGWOOD, E.GÉRARD, A.: “Objetivos y Principios Fundamentales de un Derecho Comparado de la Alimentación." Revista alimentaria número especial de la Universidad libre de Bruselas. Instituto de estudios europeos. Centro de investigación sobre el Derecho de la Alimentación, 1970.

BIRCH, L.: "Development of food preferences.” Annual review of nutrition, vol. 19, no 1, 1999.

BOURN, J.: Tackling obesity in England. The Stationery Office, London, UK, 2001.

BROWNELL, K. et al.: "Personal responsibility and obesity: a constructive approach to a controversial issue." Health Affairs, vol. 29, no 3, 2010.

BROWNELL, Kelly; HORGEN, K.: "Food fight: The inside story of the food industry, America's obesity crisis, and what we can do about it." Chicago, IL: Contemporary books, 2004.

CANDELAS, R. ALTARRIBA, M. LÓPEZ, A.: Nutrición en el climaterio. Informe de S VMFYC, Valencia, España 2016.

CASANUEVA, E. PEREZ, A. B. KAUFER, M.: Nutriología medica/Medical Nutriología. Ed. Médica Panamericana, Madrid, 2008.

CAYUELA, J.M.: Los hábitos de consumo en los modelos alimentarios. En Los modelos alimentarios a debate: la interdisciplinariedad de la alimentación. Universidad Católica San Antonio de Murcia, 2004.

${ }^{193}$ Según la jurisprudencia de la Unión Europea, se presume que un consumidor medio es aquel normalmente informado y razonablemente atento y perspicaz. Sin embargo puede que en la práctica el consumidor medio europeo no coincida con la presunción del TJEU.

${ }^{194}$ Vid. el apartado IV del capítulo I sobre los enfoques de intervención, en concreto el que tiene que ver con la responsabilidad individual. 
CASTANG, Charles: Política y Derecho alimentario en la Comunidad Económica Europea. 1992. Disponible http://repositori.uji.es/xmlui/bitstream/handle/10234/104018/Castang_Pol\%EDtica_1992.pdf?seq uence=1 Accedido el 12 de enero de 2015.

CHAN, Margaret. WHO Director-General addresses health promotion conference. En Opening Address at the 8th Global Conference on Health Promotion. 2013. Disponible en http://wphna.org/wp-content/uploads/2015/11/2013-06-10-WHO-Margaret-Chan-Helsinki.pdf. Accedido el 03 de noviembre de 2015.

DE LOMA-OSSORIO, E.:Seguridad Alimentaria y Nutricional. Conceptos Básicos. Programa Especial para la Seguridad Alimentaria-PESA-Centroamérica, Ministerio de Asuntos Exteriores de Cooperación. Agencia Española de Cooperación Internacional. FAO. 2007.

DE VOGLI, Roberto; KOUVONEN, Anne; GIMENO, Da: "The influence of market deregulation on fast food consumption and body mass index: a cross-national time series analysis". Bulletin of the World Health Organization, 2014, vol. 92, no 2.

DREWNOWSKI, Adam; SPECTER: "Poverty and obesity: the role of energy density and energy costs". The American journal of clinical nutrition, 2004, vol. 79, no 1.

DREWNOWSKI, Adam: "Obesity and the food environment: dietary energy density and diet costs". American journal of preventive medicine, 2004, vol. 27, no 3.

DREWNOWSKI, Adam: "The real contribution of added sugars and fats to obesity". Epidemiologic reviews, 2007, vol. 29, no 1.

EICHER-MILLER, Heather; FULGONI, Victor; KEAST, Debra: "Contributions of processed foods to dietary intake in the US from 2003-2008: a report of the Food and Nutrition Science Solutions Joint Task Force of the Academy of Nutrition and Dietetics, American Society for Nutrition, Institute of Food Technologists, and International Food Information Council." The Journal of nutrition vol. 142, no 11, 2012.

GUTIERREZ,J.B.: Ciencia Bromatológica. Principios generales de los alimentos, Madrid 2000.

HERRERA, R.: La bipolaridad del Derecho alimentario. En UE, Sociología y Derecho alimentarios: estudios jurídicos en honor de Luis González Vaqué. Ed. Aranzadi, 2013.

KATZ, M. H: "Structural interventions for addressing chronic health problems." JAMA, vol. 302, no 6, 2009.

LUDWIG, D. S.: “Technology, diet, and the burden of chronic disease”. JAMA, vol. 305, no 13. 2011.

LUSTIG, R. H.: Fat chance: beating the odds against sugar, processed food, obesity, and disease. Penguin, 2012.

MARTínEZ, J. A. ANCHÍA, I. A. FRITSCH, H.M.: Alimentación y salud pública. Ed. McGraw-Hill Interamericana, 2002. 
MENDEZ ROCASOLANO, Marçía: "Versión actual de dignidad de la persona: un nuevo paradigma para los derechos humanos en época de crisis" en Problemática de los derechos humanos fundamentales en américa latina y europa desafios materiales y de eficacia, Marcial Pons , 2012.

MONTEIRO C, CANNON G, LEVY RB, Claro RM, MOUBARAC J-C.: The Food System. The big issue. [Position paper] World Nutrition December 2012, 3, 12.

MONTEIRO CA, CANNON G, LEVY RB et al.: "NOVA. The star shines bright. [Food classification. Public health]" World Nutrition January-March 2016, 7.

MONTEIRO Carlos: "The Food System. Ultra-processing. The big issue for nutrition, disease, health, well-being”. World Nutrition, 3, 12. December 2012.

MONTEIRO, C. A.: "The big issue is ultra-processing. There is no such thing as a healthy ultraprocessed product.[Commentary]". Journal of the World Public Health Nutrition Association, 2011, vol. 7.

MONTEIRO, Carlos A. et al.: "Ultra-processed products are becoming dominant in the global food system". Obesity reviews, 2013, vol. 14, no S2.

MOODIE, R. et al.: "Profits and pandemics: prevention of harmful effects of tobacco, alcohol, and ultra-processed food and drink industries". The Lancet, 2013, vol. 381, no 9867. 2013.

MOSS, M.: Salt, sugar, fat: how the food giants hooked us. Random House, 2013.

MOUBARAC, J.C. et al.: "Food classification systems based on food processing: significance and implications for policies and actions: a systematic literature review and assessment". Current obesity reports, vol. 3, no 2,. 2014.

N GEARHARDT, Ashley, et al.: "The addiction potential of hyperpalatable foods". Current drug abuse reviews, 2011, vol. 4, no 3.

ONETE, Bogdan Cristian, et al.: "Researching the gap between foodstuff's attractiveness and real nutritional profile-prerequisite for strengthening nutrition education and consumer rights protection". Amfiteatru Economic, 2014, vol. 16, no 36.

PANJWANI, Clare; CARAHER, Martin: "The Public Health Responsibility Deal: brokering a deal for public health, but on whose terms?". Health Policy, 2014, vol. 114, no 2.

PEREIRA, Mark A. et al.: "Fast-food habits, weight gain, and insulin resistance (the CARDIA study): 15-year prospective analysis". The lancet, 2005, vol. 365, no 9453.

PICASSO, Rafael Repullo: Nutrición humana y dietética: la alimentación en la salud y en la enfermedad. Marbán, 2001.

POMERANZ, Jennifer L.; ROBERTO, Christina A.: "The Impact of 'Food Addiction'on Food Policy”. Current Addiction Reports, 2014, vol. 1, no 2.

RECUERDA GIRELA, Miguel Ángel: "Los principios generales del derecho alimentario 
europeo.” Revista de derecho de la Unión Europea, no 26, 2014.

RECUERDA GIRELA, Miguel Ángel: Tratado de Derecho Alimentario. Aranzadi, Pamplona 2011.

ROBERTO, Christina A. et al.: "Patchy progress on obesity prevention: emerging examples, entrenched barriers, and new thinking”. The Lancet, 2015, vol. 385, no 9985.

ROJAS MORENO Rafael.: Nutrición y dietética para tecnólogos de los alimentos. Ediciones Díaz de Santos, 2013, pág. 199.

SLIMANI, N. et al.: "Contribution of highly industrially processed foods to the nutrient intakes and patterns of middle-aged populations in the European Prospective Investigation into Cancer and Nutrition study". European journal of clinical nutrition, 2009, vol. 63.

SMITH, A. F.: "Fast Food and Junk Food" An Encyclopedia of What We Love to Eat [2 volumes]: ABC-CLIO, 2011.

STUCKLER, Da, et al.: "Manufacturing epidemics: the role of global producers in increased consumption of unhealthy commodities including processed foods, alcohol, and tobacco". PLoS Med, 2012, vol. 9, no 6.

STUCKLER, Da; NESTLE, Marion: "Big food, food systems, and global health". PLoS Med, 2012, vol. 9, no 6 .

SWINBURN, Boyd A. et al.: "The global obesity pandemic: shaped by global drivers and local environments.” The Lancet, 2011, vol. 378, no 9793.

SWINBURN, Boyd, et al:: "Strengthening of accountability systems to create healthy food environments and reduce global obesity". The Lancet, 2015, vol. 385, no 9986.

TAVARES, Letícia Ferreira, et al:: "Relationship between ultra-processed foods and metabolic syndrome in adolescents from a Brazilian Family Doctor Program". Public health nutrition, 2012, vol. 15, no 01.

THOW, Anne Marie; HAWKES, Corinna: "The implications of trade liberalization for diet and health: a case study from Central America" Globalization and health, 2009, vol. 5, no 1.

TINOCO, C.; LUGO, S.: "El trabajo no es artículo de comercio". Revista Latinoamericana de Derecho Social, 2013, vol. 17.

VAN DER MEULEN, Bernd MJ. "The structure of European food law." Laws, 2013, vol. 2, no 2.

YANCEY, Antronette K. et al.: "A cross-sectional prevalence study of ethnically targeted and general audience outdoor obesity-related advertising." Milbank Quarterly, 2009, vol. 87, no 1. 